"ESTABILIDAD DE EMULSIONES MÚLTIPLES AGUA-EN-ACEITEEN-AGUA: INFLUENCIA DE LAS PROPIEDADES INTERFACIALES DE LA MEMBRANA DEL GLÓBULO DE GRASA LÁCTEA"

\author{
TESIS \\ PARA OBTENER EL GRADO DE \\ DOCTOR EN BIOTECNOLOGÍA \\ PRESENTA \\ JORGE GUSTAVO DZUL CAUICH
}

CoDirección

Dr. E. Jaime Vernon Carter

Dra. Consuelo S. O. Lobato Calleros

MEXICO, D.F.

Julio del 2014 
El Doctorado en Biotecnología de la Universidad Autónoma Metropolitana está incluido en el Programa Nacional de Posgrados de Calidad (PNPC) del CONACYT, con la referencia 001466. 
El jurado designado por la División de Ciencias Biológicas y de la Salud de la Unidad Iztapalapa aprobó la tesis

\title{
"ESTABILIDAD DE EMULSIONES MÚLTIPLES AGUA-EN-ACEITE-EN-AGUA: INFLUENCIA DE LAS PROPIEDADES INTERFACIALES DE LA MEMBRANA DEL GLÓBULO DE GRASA LÁCTEA"
}

\author{
Que presentó \\ Jorge Gustavo Dzul Cauich
}

\section{Comité Tutorial}

Codirector: Dr. E. Jaime Vernon Carter

Universidad Autónoma Metropolitana Iztapalapa

Codirectora: Dra. Consuelo S. O. Lobato Calleros

Universidad Autónoma Chapingo

Asesor: Dr. Juan Pablo Pérez Orozco

Instituto Tecnológico de Zacatepec

\author{
Jurado \\ Presidente: Dr. Francisco Cruz Sosa \\ Universidad Autónoma Metropolitana Iztapalapa \\ Secretario: Dra. Ofelia Sandoval Castilla \\ Universidad Autónoma Chapingo \\ Vocal: $\quad$ Dr. Cesar Ramírez Santiago \\ Universidad Autónoma Chapingo \\ Vocal: Dr. Antonio Bernabé Antonio \\ Iniversidad Autónoma del Fstado de Morelos
}

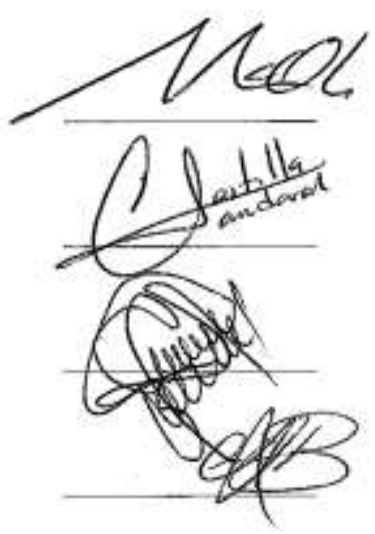




\section{Agradecimientos}

A Dios por darme las fuerzas y no decaer en los momentos difíciles.

A mis asesores Dr. E. Jaime Vernon Carter, Dra. Consuelo Lobato Calleros y Dr. Juan Pablo Pérez Orozco, por su apoyo e interés dedicado a este trabajo.

A los sinodales Dr. Francisco Cruz Sosa, Dra. Ofelia Sandoval Castilla, Dr. Cesar Ramírez Santiago y Dr. Antonio Bernabé Antonio.

A la Universidad Autónoma Metropolitana (UAM-Iztapalapa) y Universidad Autónoma Chapingo por apoyarme en la realización de este trabajo.

A cada uno de los miembros de mi familia por apoyarme alentándome a continuar con este trabajo en esos momentos difíciles, en especial a mi esposa Guadalupe Crispín Isidro y a mi nena Angélica Nicte-Ha Dzul Crispín.

A cada uno de mis amigos de la Universidad Autónoma Chapingo que me apoyaron e hicieron mi estancia agradable en el laboratorio. 


\section{Dedicado a:}

A la familia Dzul Cauich

A la familia Crispín Isidro en especial a Raúl y Silvia

A mi esposa Guadalupe Crispín Isidro

A mi Hija Angélica Nicte-Ha Dzul Crispín

A mis padrinos Oscar, Cesar, Eligio, Jhonatan, Clemente, Gerardo (Chino) y Antonio Jr.

A mis Amigos Mario “Chiken” Edgar, Benjamin, Laura E. (Ch.a.s.M) 
INDICE GENERAL

INDICE DE FIGURAS iii

INDICE DE TABLAS iv

RESUMEN $\quad$ v

ABSTRACT vi

1. INTRODUCCION 1

2. ANTECEDENTES 3

2.1 Membrana del glóbulo de grasa láctea 3

2.1.1 Composición 3

2.1.1.1 Lípidos 4

2.1.1.2 Proteínas 4

2.1.2 Aislamiento 5

2.1.3 Propiedades nutracéuticas 5

2.1.4 Propiedades emulsificantes 6

2.2 Emulsiones múltiples $\quad 6$

2.2.1 Mecanismos de estabilización $\quad 7$

2.2.2 Ventajas y limitaciones

2.2.3 Aplicaciones 8

2.3 Reología interfacial $\quad 8$

3. JUSTIFICACIÒN 10

4. OBJETIVOS 11

4.1 General 11

4.2 Particulares 11

5. HIPOTESIS 12

6. MATERIALES Y MÈTODOS 13

6.1 Aislamiento de la membrana del glóbulo de grasa láctea (MGGL) 13

6.2 Determinación de proteína total, lípidos totales y fosfolípidos de la MGGL 14

6.3 Reología interfacial 15

6.4 Viscosidad interfacial 16

6.5 Estudios de creep compliance interfacial-tiempo 16

6.6 Preparación de las emulsiones múltiples 17

6.7 Morfología y tamaño de las gotas de las emulsiones múltiples (EM) 17 
6.8 Propiedades reológicas oscilatorias de las emulsiones múltiples (EM)

6.9 Análisis de datos

7. RESULTADOS Y DISCUSIÓN

7.1 Rendimiento y composición química de la MGGL

7.2 Propiedades reológicas interfaciales de las películas de MGGL

7.2.1 Viscosidad interfacial de corte

7.2.2 Estudios de creep compliance interfacial-tiempo

7.3 Morfología y estabilidad de las EM

7.3.1 Propiedades reológicas oscilatorias de las EM

8. CONCLUSIONES

9. REFERENCIAS 


\section{INDICE DE FIGURAS}

Figura 1. Relación esfuerzo cortante-deformación con el tiempo de envejecimiento de las películas de MGGL a diferentes concentraciones: (a) $4 \%$, (b) $5 \%$ y (c) $6 \%$ Figura 2. Desarrollo de la viscosidad interfacial de corte de películas de MGGL a diferentes concentraciones con el tiempo de envejecimiento.

Figura 3. Curvas de creep compliance-tiempo de las películas MGGL y MGGL + PGPR con un tiempo de envejecimiento de $36 \mathrm{~h}$.

Fig. 4. Imágenes de microscopía óptica de gotas de las EM, constituidas por gotas esféricas de aceite conteniendo un gran número de gotas de agua: (a) $\mathrm{EM}_{4} \%$, (b) $\mathrm{EM}_{5} \%$, y (c) $\mathrm{EM}_{6} \%$. Barra de escala $=10 \mu \mathrm{m}$.

Figura 5. Cambios en el diámetro volumétrico superficial medio de gota $\left(\mathrm{d}_{3,2}\right)$ de las EM con el tiempo de almacenamiento.

Figura 6. Evolución de los módulos de almacenamiento (G') y pérdida (G') de las EM durante barridos de frecuencia a $0.2 \%$ de deformación. 
INDICE DE TABLAS

Tabla 1. Parámetros viscoelásticos de las películas interfaciales MGGL y MGGL + PGPR 


\section{RESUMEN}

La viscosidad de corte interfacial $\left(\eta^{\text {int }}\right)$ y el comportamiento creep compliance-tiempo $(\mathrm{J}(\mathrm{t}))$ de películas de membrana de glóbulo de grasa láctea (MGGL) $(4,5,6 \%$ p/p) formadas en la interfase aceite-agua, fueron evaluados. Las películas con mayor concentración de MGGL mostraron mayores $\eta^{\text {int }}$ y propiedades viscoelásticos interfaciales. Cuando se adicionaron ésteres de ácidos grasos de poliglicerol y poliricinoleato (PGPR) a la fase oleosa, una adsorción competitiva entre PGPR y MGGL tomó lugar en la interfase, lo cual causó una disminución en las propiedades viscoelásticas interfaciales de las películas. El cambio en el comportamiento reológico de las películas sugiere que su estructura interfacial fue determinada por interacciones complejas entre moléculas de MGGL y PGPR. Al aumentar la concentración de MGGL en la fase acuosa externa las emulsiones múltiples (EM) agua-en-aceite-en-agua presentaron gotas de menor diámetro volumétrico superficial $\left(\mathrm{d}_{3,2}\right)$, mayor estabilidad y más altos módulos de almacenamiento $\left(\mathrm{G}^{\prime}\right)$ y de pérdida $\left(G^{\prime \prime}\right)$.

Palabras clave: membrana del glóbulo de grasa láctea, ésteres de ácidos grasos de poliglicerol y poliricinioleato, estabilidad de las emulsiones múltiples, propiedades reológicas interfaciales. 


\begin{abstract}
The interfacial shear viscosity $\left(\eta^{\text {int }}\right)$ and the creep compliance-time $(\mathrm{J}(\mathrm{t}))$ behavior of milk fat globule membrane (MGGL) films $(4,5$ and $6 \% \mathrm{w} / \mathrm{w})$ formed at the water-oil interface were evaluated. Films with higher MGGL concentration displayed higher $\left(\eta^{\text {int }}\right)$ and interfacial viscoelastic properties. When esters of polyglycerol and polyriciniolate fatty acids (PGPR) were added to the oil phase, a competitive adsorption at the interface took place between PGPR and MGGL which caused a decrease in the interfacial viscoelastic properties of the films. The change in the rheological behavior of the films suggests that their interfacial structure was determined by complex interactions between the MFGM and PGPR molecules. Water-in-oil-in-water multiple emulsions (ME) with smaller surfacevolume droplet size $\left(\mathrm{d}_{3,2}\right)$, greater stability, and higher storage $\left(\mathrm{G}^{\prime}\right)$ and loss $\left(\mathrm{G}^{\prime}\right)$ moduli were obtained when higher MGGL concentrations were used in the outer aqueous phase.
\end{abstract}

Keywords: milk fat globule membrane, esters of polyglycerol polyriciniolate fatty acids, multiple emulsions stability, bulk and interfacial rheological properties. 


\section{INTRODUCCIÓN.}

La grasa láctea existe como una emulsión de pequeños glóbulos de grasa dispersos en el lactosuero (Jensen, 2002). El diámetro de los glóbulos de grasa láctea varía de 0.2-15 $\mu \mathrm{m}$ y están rodeados por una membrana multicapa (MGGL) de 4 a $10 \mathrm{~nm}$ de grosor, compuesta principalmente por triglicéridos, proteínas y fosfolípidos (Danthine y col., 2000; Singh, 2006). La MGGL asegura la integridad estructural, protección y estabilidad de la grasa láctea en la fase acuosa (Ye y col., 2002; Bezelgues y col., 2009). Varios estudios han indicado que algunos de los componentes de la MGGL tienen funciones benéficas para la salud, además de poseer excelentes propiedades de emulsificantes (Kanno, 1998; Corredig y Dalgleish, 1998; Roesch y col., 2004; Thompson y Singh, 2006; Singh, 2006; Bezelgues y col., 2009). Los fosfolípidos y algunas proteínas han mostrado tener actividad inhibitoria contra cáncer de mama y reducir el número de tumores de colon (Spitsberg, 2005; Singh, 2006). También los fosfolípidos han mostrado efectos benéficos contra el desarrollo de la enfermedad de Alzheimer (Parodi, 2001; Spitsberg, 2005), protección del hígado (Koopman y col., 1985) y mejoramiento de la memoria (Crook y col., 1991).

En la leche, la capa proteína-fosfolípido actúa como un surfactante para prevenir la coalescencia y floculación de los glóbulos de grasa láctea en su ambiente acuoso (Beselguez y col., 2009). Mezclas de proteínas y fosfolípidos no se encuentran solamente en la naturaleza, como en biomembranas, sino también son ampliamente usadas para estabilizar emulsiones y espumas en la industria alimentaria (Henry y col., 2010). Así, el estudio del comportamiento de adsorción y reología interfacial de películas formadas por fosfolípidos/proteína puede generar conocimiento que permita un mayor entendimiento sobre la actividad interfacial y estabilidad de emulsiones (He y col., 2008).

Las propiedades únicas de la MGGL han llevado a la investigación de tecnologías para el aislamiento y separación de materiales MGGL-enriquecidos a partir de leche. Materiales MGGL-enriquecidos potencialmente pudieran ser incorporados a emulsiones alimentarias, pudiendo así resultar nuevos alimentos funcionales y nutracéuticos. La MGGL es liberada en la fase acuosa durante el batido de la crema (desestabilización de los glóbulos de la grasa láctea) para obtener mantequilla, dando como resultado un subproducto llamado suero de mantequilla. El suero de mantequilla es de bajo costo y está disponible en grandes cantidades, pero se ha considerado durante muchos años como un producto de bajo valor. 
Sin embargo, en las últimas dos décadas ha recibido atención considerable debido a su composición especifica en proteínas y lípidos polares presentes en la MGGL (Vanderghem y col., 2010).

Por otro lado existe una necesidad de sistemas de liberación comestibles para encapsular, proteger y liberar componentes bioactivos y funcionales lipofílicos e hidrofílicos en la industria alimentaria y farmacéutica. En este sentido las emulsiones múltiples (EM) pudieran ser usadas para numerosos propósitos, incluyendo la liberación de componentes bioactivos en sitios específicos en el tracto gastrointestinal y para el diseño de matrices alimenticias que retarden la digestión lipídica (McClements y Li, 2010). Las gotas de las emulsiones múltiples agua-en-aceite-en-agua usadas en la industria alimentaria y farmacéutica pueden ser estabilizadas por una variedad de diferentes emulsificantes, incluyendo moléculas pequeñas surfactantes, biopolímeros y fosfolípidos. En particular, es importante que estos sistemas de liberación puedan ser fabricados a partir de ingredientes de grado alimenticio, usando operaciones de proceso económicamente viables, y que además sean lo suficientemente estables durante a través de su aplicación en alimentos. 


\section{ANTECEDENTES}

\subsection{Membrana del glóbulo de grasa láctea (MGGL)}

En leche cruda, el tamaño del glóbulo graso varía entre 0.2 a $20 \mu \mathrm{m}$ de diámetro. La distribución del tamaño depende de un gran número de factores, incluyendo la alimentación de la vaca y el estado de lactación. Mientras que la mayoría de los glóbulos de la grasa láctea son menores a $1 \mu \mathrm{m}$ de diámetro, más triglicéridos son transportados por un pequeño número relativo de grandes gotas de grasa en la leche. Por otro lado, los pequeños glóbulos de grasa contienen relativamente menos triglicéridos y relativamente más fosfolípidos, glicoproteínas y enzimas, ya que tienen más material de membrana por unidad de grasa que los glóbulos grandes (Zanabria-Eyzaguirre y Corredig, 2011).

El glóbulo de la grasa láctea está cubierto por la membrana (MGGL), la cual lo protege de la coalescencia y de la degradación enzimática por lipasas. Esta membrana se origina a partir de la célula mamaria y está compuesta, en glóbulos de grasa nativos de (1) una monocapa interna de lípidos polares la cual rodea a los lípidos de la gota de grasa, (2) una cubierta proteínica, (3) una bicapa de lípidos polares y proteínas. La MGGL no es homogénea y varios componentes están distribuidos diferencialmente a través de su estructura. Mientras algunas proteínas de la membrana están localizadas en la parte interna o externa, los grupos carbohidratos de las glicoproteínas y gangliósidos están expuestos principalmente en la superficie del glóbulo (Zanabria-Eyzaguirre y Corredig, 2011).

\subsubsection{Composición}

Como resultado del batido de la crema durante la elaboración de la mantequilla, la fase acuosa se libera y se recupera como un subproducto comúnmente llamado suero de mantequilla. Mientras que el material original (crema) está compuesta principalmente de proteínas derivadas de la leche (caseínas, proteínas de lactosuero, etc.) y glóbulos de grasa polidispersos, el suero de mantequilla contiene proteínas de leche descremada y también es rico en proteínas y fosfolípidos derivados de la MGGL original. Como consecuencia, el suero de mantequilla puede contener arriba de 7 veces más fosfolípidos que la leche entera (Zanabria-Eyzaguirre y Corredig, 2011). La cantidad y la composición de la MGGL 
pueden variar considerablemente dependiendo del contenido de grasa, tamaño del glóbulo y el proceso aplicado durante y después de la extracción de la leche (agitación, calentamiento, enfriamiento, homogenización, evaporación y secado) (Singh, 2006).

\subsubsection{Lipidos}

Los lípidos de la MGGL son principalmente lípidos polares, aunque también se pueden producir lípidos neutros. Estos últimos son triglicéridos, diglicèridos, monoglicèridos, colesterol y ésteres. Los lípidos polares son un componente menor de la grasa láctea, se encuentra de entre 0.2 a $1 \%$ del total de los lípidos. La cantidad de lípidos polares consisten de fosfolípidos y esfingolípidos. Estos son moléculas amfifílicas con una cola hidrofóbica y una cabeza hidrofílica (Dewettinck y col., 2008). La secreción de pequeños glóbulos de grasa con gran área superficial permite una alta relación MGGL/triglicéridos en comparación con glóbulos de grasa más grande. Por ejemplo la MGGL de leche de vaca, contiene $3.6 \pm 0.7 \mathrm{mg} / \mathrm{g}$ de grasa de lípidos polares (Menard y col., 2010). Los fosfolípidos presentes en la membrana son principalmente fosfatidilcolina, fosfatidil etanolamina, esfingomielina, fosfatidil inositol, fosfatidilserina (Fong y col., 2007; Thompson y Singh, 2006; Danthine y col., 2000).

\subsubsection{Proteínas}

Los datos reportados sobre la composición de la MGGL son altamente variables debido a los diferentes métodos de aislamiento, tipo de material, pre tratamiento del suero de mantequilla o de la crema, técnicas de purificación y de análisis. Singh (2006) informó que el contenido de proteína se encuentra entre 25-60 \% de la masa de la MGGL, dependiendo del método de aislamiento y de la muestra. Fong y col. (2007) reportaron un contenido de proteína de $22.3 \pm 1.5 \%$. Kanno y Kim (1990) encontraron un contenido de proteína en MGGL de $28 \%$. Bezelgues y col. (2009) informaron $55 \%$ de proteína para MGGL.

Las principales proteínas de la MGGL son la butirofilina (glicoproteína que comprende cerca del $40 \%$ del peso del total de las proteínas asociadas con la MGGL), xantinoxidasa (12\% del total de las proteínas de la MGGL), mucina, PAS III, PAS IV, PAS 6 y7 
(Periodic Acid Schiff, por sus siglas en inglés) (Lopez, 2011; Fong y col., 2007; Ye y col., 2002).

\subsubsection{Aislamiento}

La MGGL puede separarse de la crema, suero de mantequilla o de la leche; el método común para su aislamiento comprende cuatro pasos principales. Primero se descrema la leche con una descremadora, posteriormente la crema es lavada dos (Ye y col., 2002), tres (Fong y col., 2007) o más veces con agua desionizada (tres o más veces su volumen) dependiendo del experimento, con la finalidad de eliminar las caseínas. El siguiente paso involucra la ruptura de los glóbulos de grasa para liberar el material de la MGGL mediante el batido de la crema a $10{ }^{\circ} \mathrm{C}$ (Fong y col., 2007; Singh, 2006) o mediante la desestabilización de la crema calentándola a $50{ }^{\circ} \mathrm{C}$ (Bezelgues y col., 2009). El paso final consiste en recuperar la MGGL mediante centrifugación 90000-100000 × g por 60 min o mediante su precipitación a pH bajo (Singh, 2006). Por otro lado se ha reportado el uso de la micro y ultrafiltración para la separación de la MGGL del suero de mantequilla (Morin y col., 2004; Morin y col., 2006; Rombaut y col., 2007), la coagulación de las caseínas del suero de mantequilla mediante el uso de cuajo y el uso de citrato para disociar las micelas de caseína seguida por la microfiltración para colectar la MGGL (Corredig y col., 2003; Roesch y col., 2004).

\subsubsection{Propiedades nutracéuticas}

Varios estudios han demostrado que algunos componentes de la MGGL tienen funciones benéficas para la salud, además de poseer excelentes propiedades de emulsificación (Kanno, 1998; Corredig y Dalgleish, 1998; Roesch y col., 2004; Thompson y Singh, 2006; Singh, 2006; Bezelgues y col., 2009). Los fosfolípidos y algunas proteínas han mostrado tener actividad inhibitoria contra el cáncer de mama y la reducción del número de tumores de colon (Spitsberg, 2005; Singh, 2006). Así mismo los fosfolípidos han mostrado tener efectos benéficos contra el desarrollo de la enfermedad de Alzheimer (Parodi, 2001; Spitsberg, 2005), protección del hígado (Koopman y col., 1985) y mejoramiento de la memoria (Crook y col., 1991). 


\subsubsection{Propiedades emulsificantes}

Debido a su función original para estabilizar el glóbulo de grasa en la leche, la MGGL aislada de suero de mantequilla o de crema, es considerada como un material con excelente capacidad emulsificante. Lo anterior, debido principalmente a su contenido de fosfolípidos y otros materiales con actividad superficial (Roesch y col., 2004). Kanno y col. (1991) prepararon una emulsión (25\% de grasa) con varias cantidades de MGGL (20-80 mg/g de grasa). La cobertura de proteína en la superficie aumentó aproximadamente de 5 a $15 \mathrm{mg}$ de MGGL/g de grasa con un aumento en la concentración de 20 a 80 mg MGGL/g de grasa, con un aumento en la estabilidad de la emulsión. Al usar una cantidad de MGGL mayor a $80 \mathrm{mg} / \mathrm{g}$ de grasa en la emulsión, fue posible reconstituir glóbulos de grasa de la leche con una estabilidad similar a aquella de los glóbulos de grasa naturales.

Roesch y col. (2004) prepararon una emulsión aceite-en-agua con $10 \%$ de aceite. Las emulsiones que contenían > $0.25 \%$ de MGGL mostraron estabilidad contra el cremado; mientras que aquellas preparadas con $0.25 \%$ de MGGL presentaron cremado a las $24 \mathrm{~h}$ de elaboradas. Se ha concluido que puede existir una fuerte interacción entre la MGGL en la superficie y que los fosfolípidos que componen a la MGGL podrían estar involucrados en la reducción de la tensión interfacial; sin embargo no se sabe con certeza cuál de los componentes de la MGGL, los fosfolípidos, las proteínas o ambos son responsables de la actividad emulsificante de la MGGL (Singh, 2006).

\subsection{Emulsiones múltiples}

Las emulsiones agua-en-aceite-en-agua son conocidas como emulsiones múltiples o dobles $\left(\mathrm{W}_{1} / \mathrm{O} / \mathrm{W}_{2}\right)$, en donde $\mathrm{W}_{1}$ es la fase acuosa interna y $\mathrm{W}_{2}$ es la fase acuosa externa (la cual usualmente tiene diferente composición). En este tipo de emulsiones existen dos diferentes películas interfaciales, la película que rodea a la gota de agua en la emulsión $\mathrm{W}_{1} / \mathrm{O}$ y la película que rodea la gota de aceite en $\mathrm{O} / \mathrm{W}_{2}$. Por consiguiente, se necesitan dos diferentes tipos de emulsificantes para estabilizar las emulsiones W/O/W: un emulsificante soluble en aceite para las gotas internas de agua y un emulsificante hidrofílico para las gotas de aceite. En este sistema, es posible controlar el tamaño de las gotas y la concentración de las gotas de agua internas y las gotas de aceite (McClements y col., 2007). 


\subsubsection{Mecanismos de estabilización}

La estabilidad de las emulsiones múltiples está influenciada por su composición y por las condiciones de emulsificación. Para estabilizar emulsiones múltiples últimamente se han usado biopolímeros, sus mezclas o complejos biopoliméricos. El desarrollo actual de emulsiones alimenticias incluye el uso de dos o más biopolímeros para mejorar sus propiedades funcionales individuales (Ramírez-Santiago y col., 2012). Por ejemplo, se espera que el uso combinado de proteínas y polisacáridos pueda reunir el papel emulsionante de la proteína con la función estabilizadora del polisacárido (Dickinson y Euston, 1991). Las propiedades funcionales mejoradas resultantes de los complejos proteína-polisacárido en comparación con las proteínas y polisacáridos por sí solos podrían atribuirse a la estructura de sus complejos. Hay muchas maneras en las que los biopolímeros pueden interactuar a nivel molecular, y es importante determinar los parámetros que influyen en la formación de los complejos y su efecto sobre las principales propiedades funcionales que imparten a los sistemas a los que se incorporan (EspinosaAndrews y col., 2008; Schmitt y Turgeon, 2011). Se sabe que las cargas opuestas de las proteínas y polisacáridos forman complejos entre biopolímeros estables, que tienen la capacidad para formar y estabilizar emulsiones efectivamente (Ruiz-Ramos y col., 2006). Hernandez-Marin y col. (2013) emplearon complejos proteína-polisacárido para estabilizar emulsiones múltiples, las cuales fueron estables a lo largo de 21 días de almacenamiento.

\subsubsection{Ventajas y limitaciones}

Las emulsiones múltiples $\mathrm{W} / \mathrm{O} / \mathrm{W}$ tienen algunas ventajas sobre las emulsiones convencionales $\mathrm{O} / \mathrm{W}$ como sistemas acarreadores para lípidos bioactivos, además son más usadas para encapsulación, protección y liberación de componentes hidrofílicos, como minerales, vitaminas, enzimas, proteínas, péptidos bioactivos y fibras, los cuales pueden ser entrampados dentro de la fase acuosa interna (McClements y col., 2007). Las emulsiones múltiples son altamente susceptibles a desestabilizarse durante el almacenamiento o cuando son expuestas a medios de estrés comúnmente usados en la industria alimentaria, tales como fuerzas mecánicas, procesos térmicos, congelamiento y deshidratación. Las gotas de aceite en las emulsiones W/O/W son susceptibles al cremado, floculación, coalescencia y a la maduración de Ostwald. Las gotas internas de agua en las 
emulsiones W/O/W también son susceptibles a la floculación convencional y coalescencia; sin embargo, también pueden llegar a ser inestables debido a la difusión de las moléculas de agua entre las gotas internas y externas de las fases acuosas o debido a la expulsión de las gotas de agua de las gotas de aceite (Garti y Bisperink 1998; Benichou y col. 2004). Está claro que las emulsiones múltiples tienen potencial como sistemas acarreadores para lípidos bioactivos, pero aún existe un número de importantes desafíos que deben ser abordados antes de que esta tecnología pueda ser empleada con éxito dentro de la industria alimentaria.

\subsubsection{Aplicaciones}

Alguno de los pocos ejemplos en donde han sido usadas las emulsiones múltiples W/O/W, es la encapsulación de $\beta$ caroteno en donde se logró una alta eficiencia de encapsulación y retención de carotenoides (Rodriguez-Huezo y col., 2004), encapsulación de $\omega$-3 (Onuki y col., 2003; Cournarie y col., 2004). Encapsulación de componentes hidrofílicos bioactivos, tales como vitamina B (Fechner y col., 2007; Kukizaki y Goto 2007), inmunoglobulinas (Lee y col., 2004), insulina (Cournarie y col., 2004), proteínas (Su y col., 2006), aminoácidos (Weiss y col., 2005) y cloruro de sodio en donde se logró una alta eficiencia de encapsulación de hasta 95\% durante un mes de almacenamiento (Reitberg y col., 2012, Sapei y col., 2012).

\subsection{Reología interfacial}

En los sistemas dispersos, las propiedades reológicas macroscópicas se encuentran en estrecha relación con las dinámicas de adsorción y estado estructural de las moléculas adsorbidas en la interfase. Debido a esta adsorción, la interfase presenta una resistencia a la deformación, cuyo campo de estudio da origen a la llamada reología interfacial (Murray y Dickinson, 1996).

En general, la reología interfacial describe la relación funcional entre la deformación de una interfase, los esfuerzos ejercidos sobre la misma y los flujos resultantes en las fases de los líquidos adyacentes (Krägel y col., 2008). 
Existen dos tipos de deformación interfacial importantes: cambios en el área, ya sea por dilatación o compresión (reología interfacial dilatacional); cambios debido a un movimiento de corte manteniendo el área constante (reología interfacial de corte). Mientras que las propiedades interfaciales de corte contribuyen a la estabilidad a largo plazo de los sistemas dispersos, las propiedades interfaciales dilatacionales presentan una influencia importante en la estabilidad a corto plazo, que tiene que ver con los mecanismos de adsorción/desorción de las moléculas con actividad superficial en las interfases cuando éstas se están formando (Rodríguez-Patino y col., 2001; Martín y col., 2002).

Las propiedades interfaciales de corte son usadas para caracterizar las interacciones que surgen entre las macromoléculas adsorbidas en las interfases (Dickinson, 1999; Murray y Dickinson, 1996; Sánchez-González y col., 1999; Burgess y Sahin, 1997). RodríguezPatino y Rodríguez-Niño (1999) presentaron una investigación sobre la caracterización interfacial de proteínas y lípidos empleados como agentes emulsionantes, concluyendo que la composición interfacial y de la fase acuosa, así como las condiciones de operación (temperatura, presión superficial, $\mathrm{pH}$, densidad superficial, etc.) tienen un efecto sobre las características interfaciales (estructura, estabilidad, reología, etc.) de los emulsionantes (lípidos y proteínas) en interfases agua-aire.

Dickinson (1999) realizó un estudio completo sobre películas de proteínas adsorbidas en interfases fluidas, y relacionó las características de las interacciones con las características estructurales de los sistemas mediante reología superficial de corte. Otros estudios de Roth y col. (2000) presentan los efectos de tratamientos térmicos y desplazamiento por tensoactivos iónicos de las películas interfaciales formadas con $\beta$-Lactoglobulina. 


\section{JUSTIFICACIÓN}

Estudios recientes han demostrado que la composición de la membrana del glóbulo de la grasa de la leche le confiere propiedades nutracéuticas y emulsificantes; sin embargo, este material no se aprovecha en nuestro país; más aún, es desechado por las plantas productoras de derivados lácteos, aumentando de esta manera la contaminación del manto acuífero. Por otro lado, en la industria alimentaria existe la necesidad de sistemas de liberación, que encapsulen, protejan y liberen agentes bioactivos lipofílicos e hidrofílicos. En este sentido, las emulsiones múltiples pudieran ser utilizadas para diversos propósitos, incluyendo la liberación de agentes bioactivos en el tracto gastrointestinal, el diseño de matrices alimentarias que retrasen la digestión de lípidos y la estructuración de alimentos bajos en grasa. Con base en los expuesto, resulta interesante estudiar la funcionalidad de la membrana del glóbulo de grasa láctea, como agente emulsificante, en emulsiones múltiples agua-en-aceite-en-agua. 


\section{OBJETIVOS}

\subsection{General}

Estudiar la influencia de las propiedades interfaciales de películas de membrana de glóbulo de grasa láctea/ésteres de ácidos grasos de poliglicerol y poliricinioleato sobre la estabilidad y propiedades reológicas de emulsiones múltiples agua-en-aceite-en-agua.

\subsection{Particulares}

- Aislar la membrana del glóbulo de grasa de leche (MGGL).

- Determinar la viscosidad de corte interfacial y las propiedades viscoelásticas interfaciales de películas de MGGL adsorbidas en interfases aceite-agua.

- Evaluar el efecto de la adsorción competitiva entre MMGL y ésteres de ácidos grasos de poliglicerol y poliricinioleato (PGPR) sobre las propiedades viscoelásticas de las películas interfaciales.

- Evaluar la influencia de las películas interfaciales MGGL/PGPR sobre la estabilidad y las propiedades reológicas de emulsiones múltiples agua-en-aceite-en-agua. 


\section{HIPÓTESIS}

La membrana del glóbulo de grasa láctea (MGGL) forma películas interfaciales viscoelásticas en interfases aceite-agua, por lo que constituye un material emulsificante grado alimenticio con funcionalidad potencial para la obtención de emulsiones múltiples agua-en-aceite-en-agua estables. La estabilidad y las propiedades reológicas de las emulsiones múltiples dependerán de las propiedades reológicas interfaciales de las películas formadas por MGGL (emulsificante hidrofílico) y ésteres de ácidos grasos de poliglicerol y poliricinioleato (emulsificante lipofílico). 


\section{MATERIALES Y MÉTODOS}

Aceite de canola (AC; Capullo®; Unilever de México, S.A de C.V.); carboximetilcelulosa (CMC; CMC® CEROL 50 000; Grupo Dermet, S.A de C.V.); emulsificante lipofilico (PGPR; Grinsted® PGPR 90, ésteres de ácidos grasos de poliglicerol y poliricinoleato; Danisco México, S.A de C.V.); ácido clorhídrico, hidróxido de sodio, cloroformo, metanol, acido perclórico, molibdato de amonio, bisulfito de sodio, sulfito de sodio y fosfato monopotásico (J. T. Baker, S. A. de C. V. ); ácido 1-amino-2-naftol-4-sulfonico (Alta Pureza Maquiladora S. A de C. V.) fueron comprados en la Ciudad de México, México. Para todos los experimentos se utilizó agua destilada desionizada.

\subsection{Aislamiento de la MGGL}

La MGGL fue aislada a partir de crema fresca cruda siguiendo el procedimiento descrito por Fong y col. (2007) con ligeras modificaciones. Diez litros de crema cruda (40 g de grasa por 100 g; Planta Lechera, Universidad Autónoma Chapingo, Texcoco, Estado de México, México) fueron usados en cada uno de los experimentos. La crema $\left(30 \pm 1^{\circ} \mathrm{C}\right)$ fue suspendida en una solución de lavado (agua desionizada a $38 \pm 1{ }^{\circ} \mathrm{C}$ ) en una proporción de $1 \mathrm{~L}$ de crema por $3 \mathrm{~L}$ de agua aplicando agitación suave (880 rpm, $15 \mathrm{~min}$ ) con un agitador mecánico (CAFRAMO modelo RZR1, Cole-Parmer, Vernon Hills, IL, EUA). La crema fue subsecuentemente separada con una descremadora. Este paso de lavado fue repetido tres veces. La crema lavada, después de ser refrigerada toda la noche a $4 \pm 1{ }^{\circ} \mathrm{C}$, fue batida usando una batidora KitchenAid (KSMC50S KitchenAid Inc., St. Joseph, Michigan, EUA) operada a $750 \mathrm{rpm}$ a $10^{\circ} \mathrm{C}$ hasta la obtención de mantequilla y suero de mantequilla. La mantequilla fue recolectada mediante filtración a través de dos capas de tela manta de cielo, la cual fue usada para retener los gránulos de mantequilla. El pH del suero de mantequilla se ajustó a 4.8 con ácido clorhídrico $(1 \mathrm{M})$ con la finalidad de precipitar la MGGL. Las mezcla de partículas-agua resultante fue centrifugado en tubos de vidrio con una centrifuga (Sorvall RC-5B; GMI Inc., Ramsey, MN, EUA) a 10000 rpm durante 30 min para separar la MGGL insoluble. El pH de la suspensión de MGGL se ajustó a 6.8 usando hidróxido de sodio (1 M). La suspensión de MGGL se liofilizó con una 
Liofilizadora Lyph Lock® 4.5 Freeze Dryer (Labconco Corporation, MO, EUA) y el polvo resultante se almacenó a $-20{ }^{\circ} \mathrm{C}$ hasta su uso.

\subsection{Determinación de proteína total, lípidos totales y fosfolípidos de la MGGL}

El contenido total de proteína de la MGGL liofilizada fue determinado por el método Kjeldahl (AOAC, 1995), usando un factor de conversión de 6.38.

Los lípidos fueron extraídos a partir de la MGGL siguiendo el método descrito por Sánchez-Juanes y col. (2009) con ligeras modificaciones. Un gramo de MGGL en polvo se disolvió en $10 \mathrm{~mL}$ de una mezcla de cloroformo/metanol (1:1 v/v); la mezcla se agitó durante toda la noche a $4{ }^{\circ} \mathrm{C}$ y después se centrifugó a $1700 \mathrm{rpm}$ durante $10 \mathrm{~min}$ a $4{ }^{\circ} \mathrm{C}$. El "pellet" se re-homogenizó en $10 \mathrm{~mL}$ de cloroformo/metanol (2:1 v/v), se agitó durante 45 min a $4{ }^{\circ} \mathrm{C}$ y centrifugó como se describió antes. El nuevo "pellet" se re-homogenizó en 10 $\mathrm{mL}$ de cloroformo/metanol $(1: 2 \mathrm{v} / \mathrm{v})$, se agitó y se centrifugó como se describió anteriormente. Los sobrenadantes combinados se redujeron a un cuarto de su volumen original mediante secado a $40{ }^{\circ} \mathrm{C}$ en una estufa (Modelo HS-33 Ríos Rocha, Ciudad de México, México), se almacenó a $-20{ }^{\circ} \mathrm{C}$ durante toda la noche y posteriormente se centrifugó a $1700 \mathrm{rpm}$ durante $10 \mathrm{~min}$ a $4{ }^{\circ} \mathrm{C}$ para remover el material insoluble. El extracto resultante se colocó en una caja Petri y se secó en una estufa a $40{ }^{\circ} \mathrm{C}$ por $24 \mathrm{~h}$. Posteriormente, la caja Petri se colocó en un desecador, con $\mathrm{CaCl}_{2}$ como desecante, por 24 h y los lípidos totales (LT) se determinaron gravimétricamente.

Para determinar el contenido de fosfolípidos, $0.15 \mathrm{~g}$ de LT se disolvieron con cloroformo/metanol $(1: 2 \mathrm{v} / \mathrm{v})$ y diluyeron a $10 \mathrm{~mL}$. Una muestra de $1 \mathrm{~mL}$ de la dilución se tomó y secó por evaporación $\left(40^{\circ} \mathrm{C}\right)$. La determinación del contenido de fosfolípidos totales (CFT) se realizó basándose en el procedimiento descrito por Nalto (1975) con modificaciones. La muestra seca se adicionó con $0.8 \mathrm{~mL}$ de ácido perclórico ( $72 \% \mathrm{v} / \mathrm{v})$ en un tubo graduado de $15 \times 15 \mathrm{~mm}$, el cual fue colocado en baño de arena a $200{ }^{\circ} \mathrm{C}$ durante 30 min y enfriado a temperatura de laboratorio $\left(20 \pm 2{ }^{\circ} \mathrm{C}\right)$. Después, se adicionaron aproximadamente $6 \mathrm{~mL}$ de agua desionizada $+0.5 \mathrm{~mL}$ de molibdato de amonio $(5 \% \mathrm{p} / \mathrm{v})$ y $0.4 \mathrm{~mL}$ de agente reductor $(27.2 \mathrm{~g}$ de bisulfito de sodio+6 $\mathrm{g}$ de sulfito de sodio+0.5 $\mathrm{g}$ de ácido 1-amino-2-naftol-4-sulfónico, diluido a $250 \mathrm{~mL}$ ). El contenido del tubo fue diluido a 
$10 \mathrm{~mL}$ con agua desionizada. Posteriormente, la mezcla se dejó reaccionar durante $20 \mathrm{~min}$ y se procedió a la lectura de la absorbancia en un espectrofotómetro (Spectronics Genesys 5 UV/Vis, Spectronic Unicam, Rochester, NY, EUA) a $660 \mathrm{~nm}$. El espectrofotómetro se ajustó con un blanco ( $0.8 \mathrm{~mL}$ de ácido perclórico). La calibración se realizó con $0.1 \mathrm{~mL}$ de solución estándar $\left(\mathrm{KH}_{2} \mathrm{PO}_{4}, 0.5 \mathrm{mg} \mathrm{mL}{ }^{-1}=11.38 \mu \mathrm{g}\right.$ de $\mathrm{P}+0.8 \mathrm{~mL}$ de ácido perclórico $)$. El contenido total de fosfolípidos se calculó con la siguiente ecuación:

$$
C F T(m g / L)=\left(A_{s} / A_{s t d}\right) \times\left[P_{s t d} \times\left(V_{s t d} / V_{s}\right)\right] \times 25
$$

Donde CFT = contenido total de fosfolípidos $\left(\mathrm{mg} . \mathrm{L}^{-1}\right) ; \mathrm{A}_{\mathrm{s}}=$ absorbancia de la muestra; $\mathrm{A}_{\text {std }}$ $=$ absorbancia de la solución estándar; $\mathrm{P}_{\text {std }}=$ fósforo en la solución estándar $\left(\mathrm{mg} \cdot \mathrm{L}^{-1}\right) ; \mathrm{V}_{\text {std }}=$ volumen de la solución estándar $(\mathrm{mL}) ; \mathrm{V}_{\mathrm{s}}=$ volumen de la muestra $(\mathrm{mL})$ y 25 = factor para la conversión de fósforo (mg) a fosfolípidos (mg).

\subsection{Reología interfacial}

Las mediciones de reología interfacial se llevaron a cabo con un reómetro Physica MCR 301 Dynamic Shear Rheometer (Physica Meßtechnik GmbH, Stuttgart, Alemania), con una geometría bicono (radio del disco, $(\mathrm{Rb})$, de $34.125 \mathrm{~mm}$ y ángulo doble del disco $(2 \alpha)$ de $\left.10^{\circ}\right)$. Un vaso termostato (radio interno, $(\mathrm{Rc}), 40 \mathrm{~mm}$ ) fue colocado en el plato de medición del reómetro. Disoluciones acuosas (118 mL) de MGGL (4, 5, $6 \%$ p/p) a pH 7.0 preparadas $24 \mathrm{~h}$ antes, fueron colocadas cuidadosamente dentro del vaso termostatizado. Después la geometría tipo bicono fue bajada hasta la superficie de la solución de MGGL. Entonces $118 \mathrm{~mL}$ de $\mathrm{AC}$ o AC+PGPR fueron vertidos cuidadosamente por las paredes del vaso, con ayuda de una pipeta, hasta que el aceite formó una capa sobre la solución de MGGL (Román-Guerrero y col., 2009). La edad de la interfase se tomó a partir del momento en el que la última gota de aceite fue vertida. 


\subsection{Viscosidad interfacial}

Las diferentes películas interfaciales de MGGL se sometieron a una velocidad angular constante $(\Omega)$ de $1.76 \times 10^{-4} \mathrm{rad} \mathrm{s}^{-1}$. El torque necesario $(\mathrm{M})$ para mantener la velocidad rotacional constante y el desplazamiento angular del disco con el tiempo $\left(\theta_{\mathrm{b}}\right)$ fue monitoreado cada $10 \mathrm{~s}$ por $15 \mathrm{~min}$ con el software del reómetro. Se obtuvieron gráficas de deformación interfacial $\left(\gamma^{\text {int }}\right)$ contra esfuerzo interfacial $\left(\sigma^{\text {int }}\right)$ con el software del equipo, $y$ fueron usadas para determinar la región en la cual el torque y/o esfuerzo interfacial en la interfase tuvo un comportamiento constante, el cual fue usado para calcular la viscosidad interfacial $\left(\eta^{\text {int }}\right)$ con la siguiente ecuación (Pérez-Orozco y col., 2004):

$$
\eta^{\mathrm{int}}=\frac{M}{4 \pi \Omega}\left(\frac{1}{R_{b}^{2}}-\frac{1}{R_{c}^{2}}\right)
$$

\subsection{Estudios de creep compliance interfacial-tiempo}

El comportamiento deformación/esfuerzo cortante constante interfacial con el tiempo o creep-compliance interfacial-tiempo de las diferentes películas MGGL y MGGL/PGPR se estudió. Las películas se sometieron a un esfuerzo cortante interfacial constante $\left(\sigma^{\text {int }}\right)$ de $0.5658 \mathrm{mN} / \mathrm{m}$ durante $60 \mathrm{~min}$, después de lo cual el $\left(\sigma^{\mathrm{int}}\right)$ se retiró y la relajación del esfuerzo de las películas interfaciales fue monitoreada durante $7 \mathrm{~min}$. El esfuerzo cortante seleccionado cayó dentro de la región viscoelástica lineal de todas las películas interfaciales.

Se obtuvieron gráficas de $\mathrm{J}(\mathrm{t})$ contra el tiempo $(\mathrm{t})$ para las diferentes películas interfaciales y el software del equipo, proporcionó los valores de los parámetros de la siguiente ecuación (Pérez-Orozco y col., 2011):

$$
J(t)=J_{0}+J_{m}\left(1-e^{-(t / \lambda m)}\right)+J_{N}
$$

Donde $J_{0}=\left(1 / E_{0}, E_{0}\right.$ es el módulo elástico instantáneo interfacial) es la deformación elástica instantánea interfacial en la cual los enlaces entre las unidades estructurales primarias son estirados elásticamente; $J_{m}=\left(1 / E_{R}, E_{R}\right.$ es el modulo elástico de retardo 
interfacial) es la deformación de retardo media interfacial de todos los enlaces involucrados; $\lambda_{\mathrm{m}}=\left(J_{m} / \eta_{m} ; \eta_{m}\right.$ es la viscosidad media interfacial asociada con la elasticidad de retardo) es el tiempo de retardo medio interfacial; y $J_{N}=\left(t / \eta_{N}\right)$ es la deformación/esfuerzo cortante constante newtoniana interfacial, la cual es caracterizada por una viscosidad interfacial $\eta_{N}$. Todas las mediciones se realizaron a $25^{\circ} \mathrm{C}$.

\subsection{Preparación de las emulsiones múltiples (EM)}

Se prepararon tres emulsiones múltiples (EM) a $20 \pm 2{ }^{\circ} \mathrm{C}$ usando un procedimiento de emulsificación de dos etapas (Lobato-Calleros y col., 2009). En la primera etapa se preparó una emulsión $\mathrm{W}_{1} / \mathrm{O}$ con una fracción másica dispersa de $0.3\left(\varnothing_{1}\right)$. La fase acuosa $\left(\mathrm{W}_{1}\right)$ (29.9 g de agua destilada $+0.1 \mathrm{~g}$ de $\mathrm{CMC}$ ) se adicionó gota a gota con agitación continua a la fase oleosa (66.8 g de AC + 3.2 g de PGPR) mediante un homogeneizador (Ultraturrax ${ }^{\circledR}$ T50 basic IKA Works, Inc., Wilminton, EUA) operado a $6400 \mathrm{rpm}$ por $5 \mathrm{~min}$. En la segunda etapa la cantidad de emulsión primaria $\mathrm{W}_{1} / \mathrm{O}$ requerida fue re-emulsificada (6400 rpm por $4 \mathrm{~min}$ ) en soluciones al 4, 5 y $6 \%$ p/p de MGGL, ajustadas a pH 7.0, obteniéndose EM con una fracción másica dispersa de $0.3\left(\varnothing_{2}\right)$, las cuales se codificaron como: $\mathrm{EM}_{4 \%}, \mathrm{EM}_{5 \%}$, y $\mathrm{EM}_{6 \%}$, respectivamente. Durante el proceso de emulsificación se usó un baño de hielo para evitar el aumento de temperatura por arriba de $20 \pm 2{ }^{\circ} \mathrm{C}$.

\subsection{Morfología y tamaño de las gotas de las EM}

La morfología de las gotas de las EM fue determinada usando un microscopio óptico (Olympus BX45, Olympus Optical Co., Tokio, Japón) acoplado a un sistema analizador de imágenes (digital Olympus cámara C3030, Olympus América Inc., EUA).

El diámetro volumétrico-superficial medio de las gota $\left(\mathrm{d}_{3,2}\right)$ inicial y su evolución con el tiempo de almacenamiento $\left(4 \pm 1^{\circ} \mathrm{C}\right)(3,7,10,15$ y $21 \mathrm{~d})$ de las EM fue determinado con un analizador de tamaño de partícula Malvern serie 2600 (Malvern Instruments, Malvern, Worcestershire, RU). 


\subsection{Propiedades reológicas oscilatorias de las emulsione múltiples EM}

El comportamiento reológico oscilatorio de las EM fue determinado después de 1 día de preparación con el reómetro Physica MCR 301 acoplado a una geometría de cilindros concéntricos de doble gap. Muestras de las EM $(3.6 \mathrm{~mL})$ se colocaron en la geometría y se dejaron reposar durante 15 min para recuperación de la estructura y alcance del equilibrio de la temperatura $\left(25^{\circ} \mathrm{C}\right)$. Barridos de amplitud (0.01-10\% de deformación) fueron llevados a cabo a frecuencia constante $(1 \mathrm{~Hz})$, con la finalidad de determinar la región viscoelástica lineal (RVL), donde las propiedades reológicas no son dependientes de la deformación o el esfuerzo. A partir de la RVL se seleccionó un valor de deformación de $0.2 \%$ para realizar barridos de frecuencia de 0.01-10 Hz. Con el software del equipo se obtuvieron los valores de los módulos de almacenamiento $\left(G^{\prime}\right)$ y de pérdida (G') como una función de la frecuencia.

\subsection{Análisis de datos}

Todos los experimentos fueron hechos por triplicado usando un diseño experimental completamente al azar. Las propiedades reológicas interfaciales de las películas de MGGL fueron analizadas usando un análisis de varianza de clasificación simple, y cuando fue apropiado se aplicaron pruebas de Tukey para determinar diferencias entre las medias. La significancia se estableció en $\mathrm{P}<0.05$. El análisis de datos se realizó con el programa Statgraphics (Statistical Graphics Corp., Manugistics, Inc., Cambridge, MA, EUA). 


\section{RESULTADOS Y DISCUSIÓN}

\subsection{Rendimiento y composición química de la MGGL}

El rendimiento de MGGL fue $3.2 \pm 0.3 \mathrm{~g} / \mathrm{L}$ de crema. Este resultado es cercano a aquel de $3.6 \pm 0.3 \mathrm{~g} / \mathrm{L}$ informado por Fong y col. (2007). Los contenidos de proteína, lípidos y fosfolípidos totales de la MGGL fueron $42.38 \pm 1.70,45.70 \pm 1.4$ y $30.05 \pm 1.2 \%$, respectivamente. Datos en la literatura sobre la composición de la MGGL son altamente variables, debido a diferencias en el método de aislamiento, tipo de material del que se extrae, pre-tratamiento del suero de mantequilla o de la crema, técnicas de purificación y de análisis. Singh (2006) informó que el contenido de proteína de MGGL se encuentra entre 25-60\%, dependiendo del método de aislamiento seleccionado y de la historia de la muestra. Fong y col. (2007) informaron contenidos de proteína y de lípidos de $22.3 \pm 1.5$ $\%$ y $71.8 \pm 1.7 \%$, respectivamente. Kanno y Kim (1990) obtuvieron una MGGL conteniendo $28 \%$ de proteína y $64 \%$ de lípidos. Bezelgues y col. (2009) encontraron $55 \%$ de proteína, $37.9 \%$ de lípidos y $25 \%$ de fosfolípidos en MGGL.

Los fosfolípidos de la MGGL son principalmente fosfatidil colina, fosfatidil etanolamina y esfingomielina, con pequeñas cantidades de fosfatidil serina $y$ fosfatidil inositol (Thompson y Singh, 2006). Todos estos fosfolípidos poseen actividad superficial. La reología interfacial es un método importante para obtener conocimiento y entendimiento sobre la actividad interfacial y estabilidad de un sistema (He y col., 2008).

\subsection{Propiedades reológicas interfaciales de las películas de MGGL}

\subsubsection{Viscosidad interfacial de corte}

Cuando dos gotas en un medio líquido se aproximan, el comportamiento del sistema es regido por la combinación de fuerzas hidrodinámicas y fuerzas superficiales. Las fuerzas hidrodinámicas permiten el flujo viscoso del medio líquido entre gotas y la distorsión de la forma de las gotas debido a la presión desarrollada entre ellas. El flujo radial del líquido entre gotas, ejerce una fuerza de corte sobre ellas, tendiendo a generar una circulación del líquido dentro de cada gota. La distorsión de las gotas es contrarrestada por la tensión superficial (interfacial), porque cualquier cambio de la forma esférica involucra un 
aumento en el área superficial (Kitchener y Musselwhite, 1969). Mientras que la viscosidad interfacial no puede causar metaestabilidad estática, puede ayudar en la estabilización dinámica mediante el retardo de la extrusión del líquido presente entre las superficies de aproximamiento de dos gotas de emulsión.

El esfuerzo de corte superficial fue medido como función de la deformación para la MGGL a diferentes concentraciones y tiempos de envejecimiento (Fig. 1). Todas las concentraciones de MGGL mostraron perfiles de esfuerzo cortante-deformación similares. Independientemente de la concentración de MGGL usada, un tiempo de envejecimiento finito (12 h para $4 \%$ de MGGL y 8 h para 5 y $6 \%$ de MGGL) tuvo que transcurrir antes de que la película interfacial produjera una respuesta elástica; esto es, el incremento en $\sigma^{\text {int }}$ es proporcional al incremento en $\gamma^{\text {int }}$. El periodo de inducción para la formación de una película interfacial pudo ser influenciado por la velocidad de difusión de los componentes con actividad superficial de la MGGL (proteínas y fosfolípidos) y su afinidad interfacial (Beverung y col., 1999). Es típico de los surfactantes macromoleculares que su adsorción hasta alcanzar el equilibrio sea muy lenta y sea prácticamente irreversible (Kitchener y Musselwhite, 1969). Conforme continuó la adsorción interfacial y el rearreglo de los componentes con actividad superficial, ocurrió mayor número de contactos moleculares interfaciales, lo que causó la formación de una película interfacial elástica, la cual sufrió cambios estructurales reversibles debido a estiramiento de los enlaces entre moléculas sin sufrir ruptura. Conforme aumentó el tiempo de envejecimiento de las películas, la magnitud del esfuerzo interfacial $\left(\sigma^{\text {int }}\right)$ en la región elástica incrementó y fue más alto al aumentar la concentración de MGGL. Las curvas exhibiendo una respuesta elástica presentaron un máximo en $\sigma^{\text {int }}$, relacionado con la cantidad de esfuerzo que las películas puede resistir antes de que su estructura ceda, seguido por una disminución en $\sigma^{\text {int }}$, indicando que el límite elástico de las películas adsorbidas ha sido rebasado y que un mecanismo de deformación viscosa comienza a ocurrir. Conforme la deformación $\left(\gamma^{\text {int }}\right)$ continua incrementándose, $\sigma^{\text {int }}$ continua disminuyendo hasta que un valor de esfuerzo cortante en estado estacionario es alcanzado (Ganzevles y col., 2006). El máximo valor de esfuerzo cortante en estado estacionario fue obtenido después de aproximadamente $36 \mathrm{~h}$, independientemente de la concentración de MGGL usada. A este tiempo de envejecimiento los valores máximos de $\sigma^{\text {int }}$ obtenidos variaron de la siguiente manera: $1.9 \mathrm{mN} / \mathrm{m}$ para $4 \%$ de MGGL $<2.2 \mathrm{mN} / \mathrm{m}$ para $5 \%$ de MGGL $<2.3 \mathrm{mN} / \mathrm{m}$ para $6 \%$ de MGGL (Fig. 1); 
mientras los valores del $\sigma^{\text {int }}$ en estado estacionario variaron como sigue: $1.31 \mathrm{mN} / \mathrm{m}$ para 4 $\%$ de MGGL $<1.64 \mathrm{mN} / \mathrm{m}$ para $5 \%$ de MGGL $<1.71 \mathrm{mN} / \mathrm{m}$ para $6 \%$ de MGGL. Se puede observar que las películas interfaciales a concentraciones mayores de MGGL, requirieron un mayor $\sigma^{\text {int }}$ para alcanzar una deformación $\gamma^{\text {int }}$ dada.
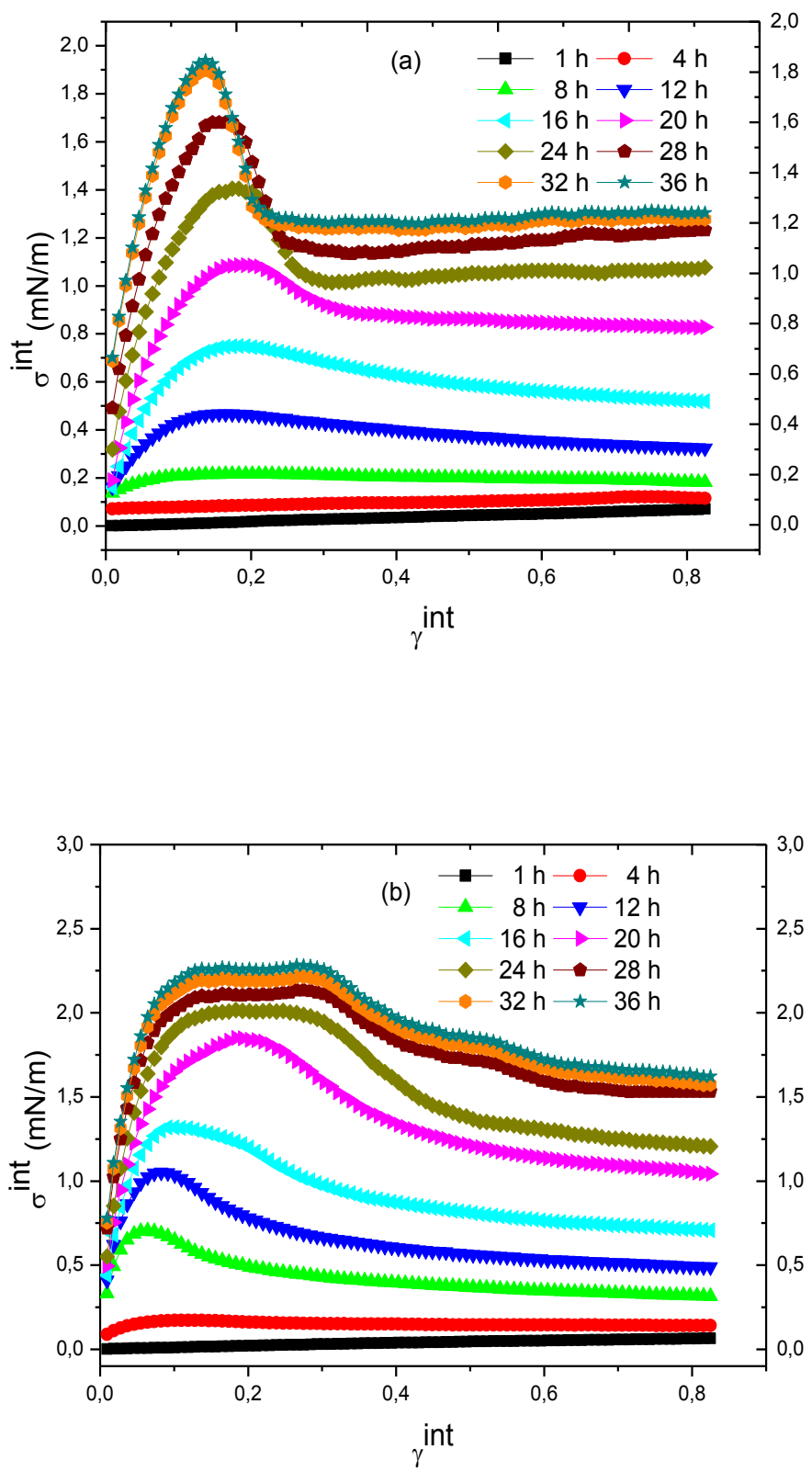


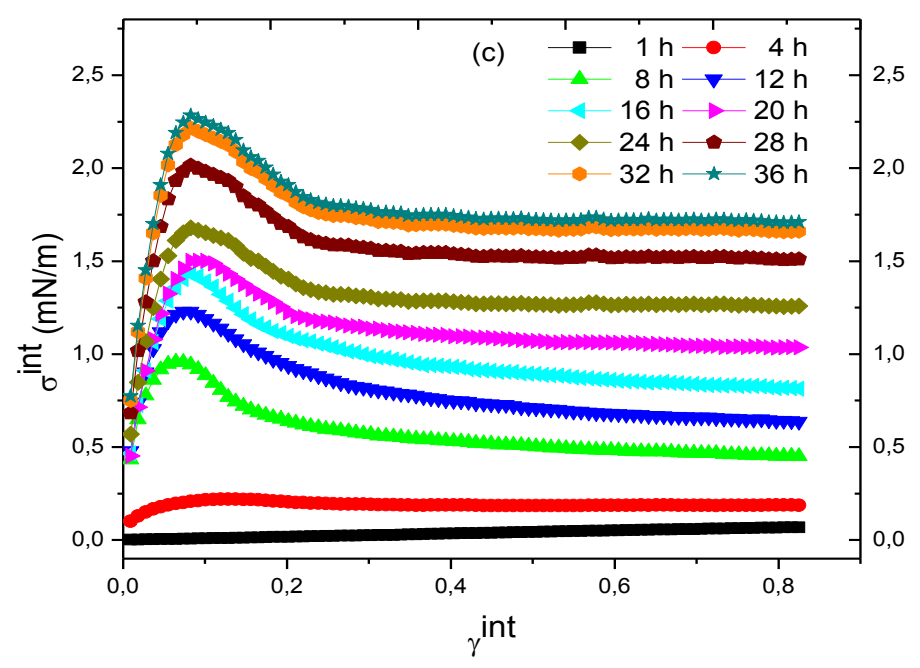

Figura 1. Relación esfuerzo cortante-deformación con el tiempo de envejecimiento de las películas de MGGL a diferentes concentraciones: (a) $4 \%$, (b) $5 \%$ y (c) $6 \%$

El esfuerzo interfacial (torque) en la interfase, donde el comportamiento estacionario fue obtenido, fue usado para calcular la viscosidad interfacial $\left(\eta^{\text {int }}\right)$. La Figura 2 muestra las gráficas de viscosidad interfacial contra tiempo para las películas usando diferentes concentraciones de MGGL. Un incremento marcado en la $\eta^{\text {int }}$ ocurrió con el tiempo de envejecimiento, indicando que las interacciones entre las moléculas de proteínas y fosfolípidos en la interfase dependió de su concentración total. El valor de $\eta^{\text {int }}$ alcanzado después de 36 h fue mayor conforme la concentración de MGGL aumentó, variando de la siguiente manera: $1029.49 \mathrm{mNs} / \mathrm{m}$ (4 \%), $1292.01 \mathrm{mNs} / \mathrm{m}(5 \%)$ y $1352.26 \mathrm{mNs} / \mathrm{m}(6 \%)$. Pérez-Orozco y col. (2004) informaron aumentos en los valores de $\eta^{\text {int }}$ para películas interfaciales formadas por goma de mezquite-quitosano con el tiempo de envejecimiento. Waninge y col. (2005) informaron que películas interfaciales elaboradas a partir de una mezcla de proteínas y fosfolípidos en semejanza a MGGL, tendió a formar estructuras más complejas que una monocapa adsorbida. 


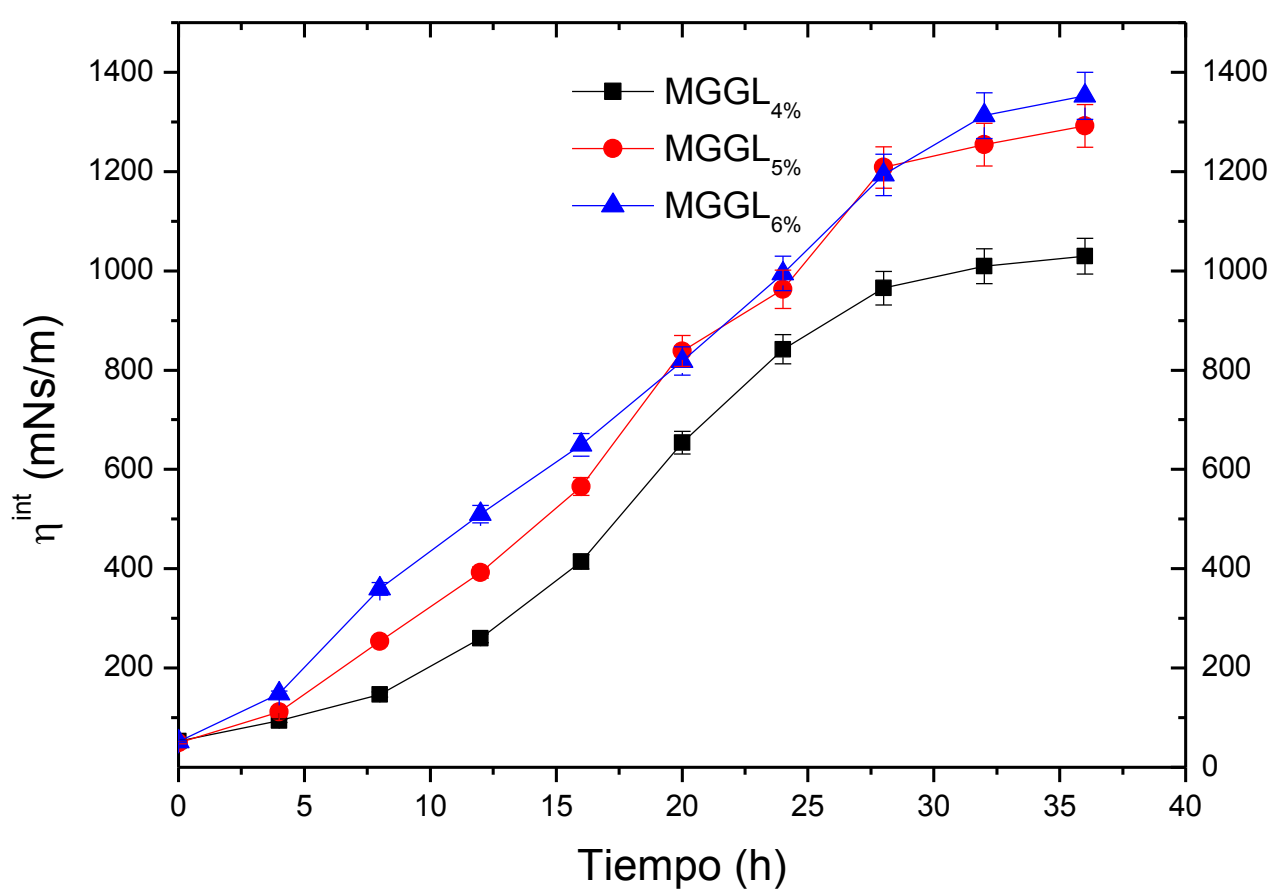

Figura 2. Desarrollo de la viscosidad interfacial de corte de películas de MGGL a diferentes concentraciones con el tiempo de envejecimiento.

\subsubsection{Estudios de creep compliance interfacial-tiempo}

Las propiedades mecánicas de interfases estabilizadas mediante macromoléculas han sido correlacionadas con la estabilidad de gota. La mecánica de aproximación de dos gotas en un medio fluido puede dar lugar a varios fenómenos, la mayoría de ellos ocasionando deformación superficial de las gotas, la cual en turno causa el adelgazamiento externo de las películas interfaciales, su colapso y coalescencia de las gotas. Se ha propuesto que las películas interfaciales que exhiben alta elasticidad poseen una mejor capacidad de soportar perturbaciones en la región interfacial, y de ese modo el tiempo de coalescencia de las gotas es grandemente extendido (Kitchener y Musselwhite, 1969). El estudio de creep compliance interfacial-tiempo es una prueba no destructiva que permite la determinación de los parámetros reológicos bajo condiciones que se aproximan al estado de la muestra en reposo; esto permite una elucidación más precisa del estado actual de la película (RománGuerrero y col., 2009). Todas las películas interfaciales (MGGL y MGGL/PGPR) 
exhibieron curvas típicas de creep compliance interfacial-tiempo (Fig. 3), indicando que las películas mostraron comportamiento viscoelástico.

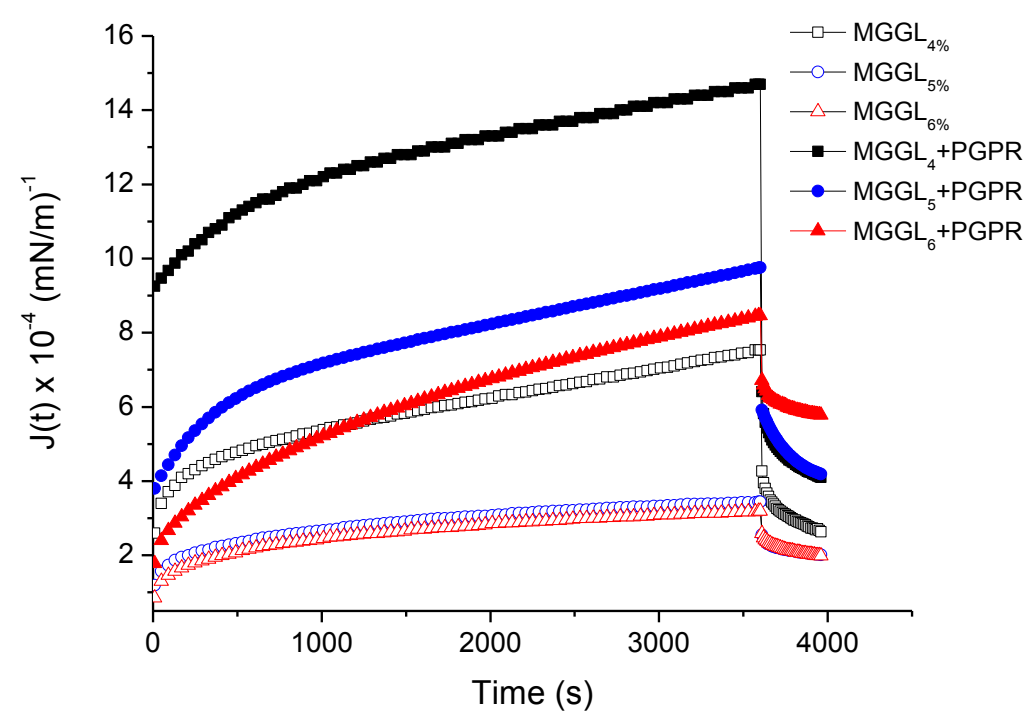

Figura 3. Curvas de creep compliance-tiempo de las películas MGGL y MGGL + PGPR con un tiempo de envejecimiento de $36 \mathrm{~h}$.

Los parámetros viscoelásticos que caracterizaron a cada película se presentan en la Tabla 1. El análisis del módulo de deformación/esfuerzo cortante constante interfacial instantáneo $\left(\mathrm{J}_{0}\right)$, el cual está relacionado con la deformación instantánea reversible sufrida por la deformación aplicada a la película, indica que conforme aumenta la concentración de MGGL (sola o combinada con PGPR) el valor de $\mathrm{E}_{0}=\left(1 / \mathrm{J}_{0}\right)$ aumenta. Así, $\mathrm{E}_{0}$, que proporciona una medida de la fuerza elástica de los enlaces que componen la estructura de la red interfacial (Lobato-Calleros y col., 2000) varió de la siguiente manera: MGGL $_{6 \%}>$ MGGL $_{5}>$ MGGL $_{6} \%+$ PGPR> MGGL $_{4 \%}>$ MGGL $_{5} \%+\mathrm{PGPR}>\mathrm{MGGL}_{4} \%+\mathrm{PGPR} . \mathrm{Los}$ parámetros de la región de deformación elástica interfacial retardada $\mathrm{J}_{\mathrm{m}} \mathrm{y} \lambda_{\mathrm{m}}\left(\mathrm{J}_{\mathrm{m}} / \eta_{\mathrm{m}}\right)$, donde los enlaces se rompen y reforman, pero no a la misma velocidad, pueden proporcionar información más detallada sobre la naturaleza de las películas interfaciales (RománGuerrero y col., 2009). En particular $\lambda_{\mathrm{m}}$ que es el tiempo necesario para que la deformación retardada alcance aproximadamente el $63.2 \%$ (1-1/ e), puede considerarse como una medida de la complejidad, del tipo y diversidad de enlaces que forman las películas interfaciales. Entre más compleja sea la estructura, se necesitan tiempos de retardo más 
prolongados para caracterizar los tipos de unión que se llevan a cabo (Lobato-Calleros y col., 2000).

Valores significativamente más altos de $\lambda_{\mathrm{m}}$ fueron observados conforme la concentración de MGGL aumentó, pero fueron significativamente más bajos para las películas MGGL+PGPR que para sus contrapartes puras MGGL. $J_{N}=\left(t / n_{N}\right)$ indica que una deformación en estado estacionario es alcanzada cuando la deformación creep es principalmente gobernada por un flujo viscoso, y es observada como un incremento lineal de la curva creep (Van Bockstaele y col., 2011). Valores más altos de $\eta_{\mathrm{N}}$ se presentaron conforme aumentó la concentración de MGGL, pero de nuevo los valores de $\eta_{\mathrm{N}}$ disminuyeron para las películas formadas por MGGL + PGPR, en comparación con las películas formadas solamente por MGGL. Para proteínas $\eta_{N}$ y G' son generalmente mucho más altos que para tensoactivos de bajo peso molecular (Murray 2011), por lo que es evidente que existe un desplazamiento de la MGGL adsorbida en la interfase por PGPR. Debido a que PGPR tiene una fuerte atracción por el aceite, sus moléculas deben encontrarse, al menos en cierta medida, disueltas en la fase oleosa. La mayor parte de la cadena hidrocarbonada de PGPR permanece dentro de la fase oleosa, y una pequeña porción de la parte hidrofílica es localizada en la interfase aceite-agua. Por otro lado, las moléculas de MGGL son más fuertemente atraídas a la fase acuosa, con sólo los restos hidrofóbicos unidos en la interfase aceite-agua y el resto de las moléculas proyectada dentro de la fase acuosa (Doxastakis y Sherman, 1983). Las moléculas de PGPR adsorbidas interrumpen la interacción entre moléculas MGGL-MGGL en la interfase, debido a una acción lubricante, pero no desplazan completamente las moléculas de MGGL de la interfase, resultando en una disminución de las propiedades viscoelásticas (Dickinson, 1991). 
Tabla 1. Parámetros viscoelásticos de las películas interfaciales MGGL y MGGL + PGPR

\begin{tabular}{lllllll}
\hline $\begin{array}{l}\text { Código de la } \\
\text { muestra }\end{array}$ & $\mathrm{J}_{0} \times 10^{4}(\mathrm{mN} / \mathrm{m})^{-1}$ & $\begin{array}{l}\mathrm{E}_{0} \times 10^{-4} \\
(\mathrm{mNm})\end{array}$ & $\mathrm{J}_{\mathrm{m}} \times 10^{4}(\mathrm{mN} / \mathrm{m})^{-1}$ & $\lambda_{\mathrm{m}}(\mathrm{s})$ & $\begin{array}{l}\mathrm{J}_{\mathrm{N}} \times 10^{4}(\mathrm{mN} / \mathrm{m})^{-} \\
1\end{array}$ & $\begin{array}{l}\eta_{\mathrm{N}} \times 10^{4} \\
(\mathrm{mNs} / \mathrm{m})^{-1}\end{array}$ \\
\hline MGGL $_{4 \%}$ & $2.59 \pm 0.12^{\mathrm{bc}}$ & $0.38 \pm 0.02^{\mathrm{b}}$ & $4.80 \pm 0.24^{\mathrm{a}}$ & $950.20 \pm 23^{\mathrm{c}}$ & $3.01 \pm 0.14^{\mathrm{bc}}$ & $1196.97 \pm 54^{\mathrm{a}}$ \\
MGGL $_{5 \%}$ & $1.20 \pm 0.06^{\mathrm{a}}$ & $0.83 \pm 0.04^{\mathrm{c}}$ & $2.21 \pm 0.18^{\mathrm{ab}}$ & $1164.76 \pm 19^{\mathrm{d}}$ & $0.82 \pm 0.05^{\mathrm{a}}$ & $4456.32 \pm 32^{\mathrm{b}}$ \\
MGGL $_{6 \%}$ & $0.85 \pm 0.04^{\mathrm{a}}$ & $1.18 \pm 0.06^{\mathrm{d}}$ & $1.81 \pm 0.13^{\mathrm{ab}}$ & $1252.89 \pm 15^{\mathrm{e}}$ & $0.73 \pm 0.02^{\mathrm{a}}$ & $4633.16 \pm 57^{\mathrm{b}}$ \\
MGGL $_{4 \%}+\mathrm{PGPR}$ & $9.18 \pm 0.66^{\mathrm{d}}$ & $0.11 \pm 0.01^{\mathrm{a}}$ & $2.47 \pm 0.17^{\mathrm{b}}$ & $322.91 \pm 10^{\mathrm{a}}$ & $3.58 \pm 0.25^{\mathrm{c}}$ & $1003.70 \pm 70^{\mathrm{a}}$ \\
MGGL $_{5 \%+P G P R}$ & $3.71 \pm 0.27^{\mathrm{c}}$ & $0.26 \pm 0.02^{\mathrm{ab}}$ & $2.62 \pm 0.18^{\mathrm{b}}$ & $472.35 \pm 14.7^{\mathrm{b}}$ & $3.42 \pm 0.12^{\mathrm{bc}}$ & $1052.10 \pm 37^{\mathrm{a}}$ \\
MGGL $_{6 \%+P G P R}$ & $1.46 \pm 0.61^{\mathrm{ab}}$ & $0.68 \pm 0.18^{\mathrm{c}}$ & $1.39 \pm 0.10^{\mathrm{a}}$ & $488.79 \pm 15.2^{\mathrm{b}}$ & $2.96 \pm 0.10^{\mathrm{b}}$ & $1213.10 \pm 40^{\mathrm{a}}$
\end{tabular}

Medias en una columna seguidas por letras diferentes son significativamente diferentes $(\mathrm{p} \leq 0.05)$. $\mathrm{J}_{0}$ : deformación/esfuerzo cortante constante interfacial instantánea; $\mathrm{E}_{0}$ : módulo elástico interfacial instantáneo; Jm: deformación/esfuerzo cortante constante media interfacial; $\lambda_{\mathrm{m}}$ : tiempo de retardo medio interfacial; $\mathrm{J}_{\mathrm{N}}$ : deformación/esfuerzo cortante constante Newtoniana; $\eta_{\mathrm{N}}$ : viscosidad interfacial. 


\subsection{Morfología y estabilidad de las EM}

Todas las emulsiones múltiples se caracterizaron por presentar morfología tipo C (Garti, 1997); es decir, estuvieron constituidas por gotas esféricas de aceite conteniendo en su interior un gran número de gotas de agua (Fig. 4). El diámetro inicial medio $\mathrm{d}_{3,2}$ de las gotas externas y su cambio con el tiempo de almacenamiento fueron considerados como una medida de la estabilidad relativa de las EM.
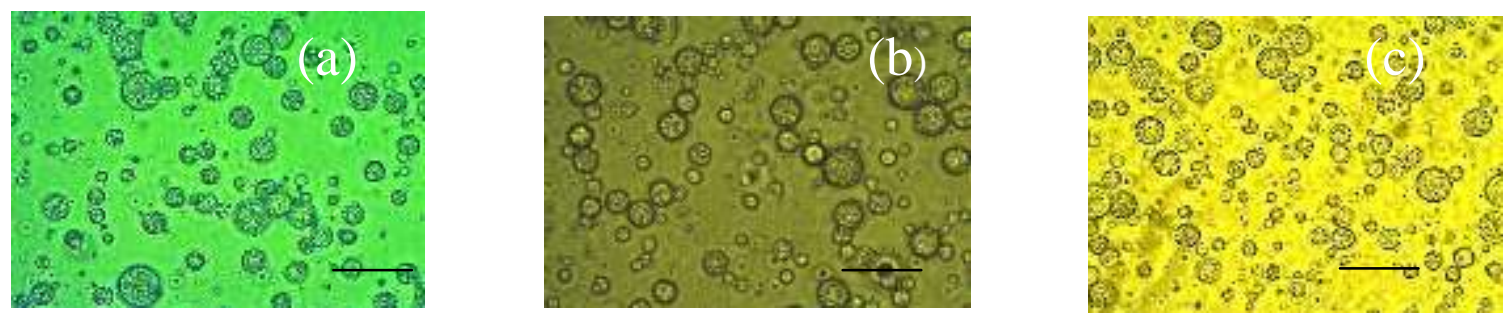

Fig. 4. Imágenes de microscopía óptica de gotas de las EM, constituidas por gotas esféricas de aceite conteniendo un gran número de gotas de agua: (a) $\mathrm{EM}_{4 \%}$, (b) $\mathrm{EM}_{5 \%}$, y (c) $\mathrm{EM}_{6 \%}$. Barra de escala $=10 \mu \mathrm{m}$.

En la Fig. 5 puede observarse que la concentración de MGGL en la fase acuosa externa influyó sobre la estabilidad de la EM y los valores iniciales $\mathrm{d}_{3,2}$. Concentraciones menores de MFGM produjeron mayores valores iniciales $d_{3,2}$ de la siguiente manera: EM $_{4 \%}(2.75$ $\mu \mathrm{m})>\mathrm{EM}_{5 \%}(2.51 \mu \mathrm{m})>\mathrm{EM}_{6 \%}(2.39 \mu \mathrm{m})$. Diámetros volumétricos superficiales iniciales más altos resultaron en mayor polidispersidad del tamaño de gota (indicado por las barras de desviación en la Fig. 5) a través del tiempo de almacenamiento. Valores iniciales $\mathrm{d}_{3,2}$ más pequeños produjeron incrementos menores en el tamaño de gota durante los 21 días de almacenamiento. Así, los incrementos relativos de $\mathrm{d}_{3,2}$ entre $\mathrm{t}=0 \mathrm{~d}$ y $\mathrm{t}=21 \mathrm{~d}$ variaron de la siguiente manera: $\mathrm{EM}_{4 \%}=4.4 \%, \mathrm{EM}_{5 \%}=2 \%$, y EM $6 \%=1.6 \%$. Estos resultados indican que aunque todas las emulsiones fueron estables, aquellas elaboradas con $6 \%$ de MGGL sufrieron la menor variación de tamaño de gota, de modo que se pueden ser consideradas como más estables. 


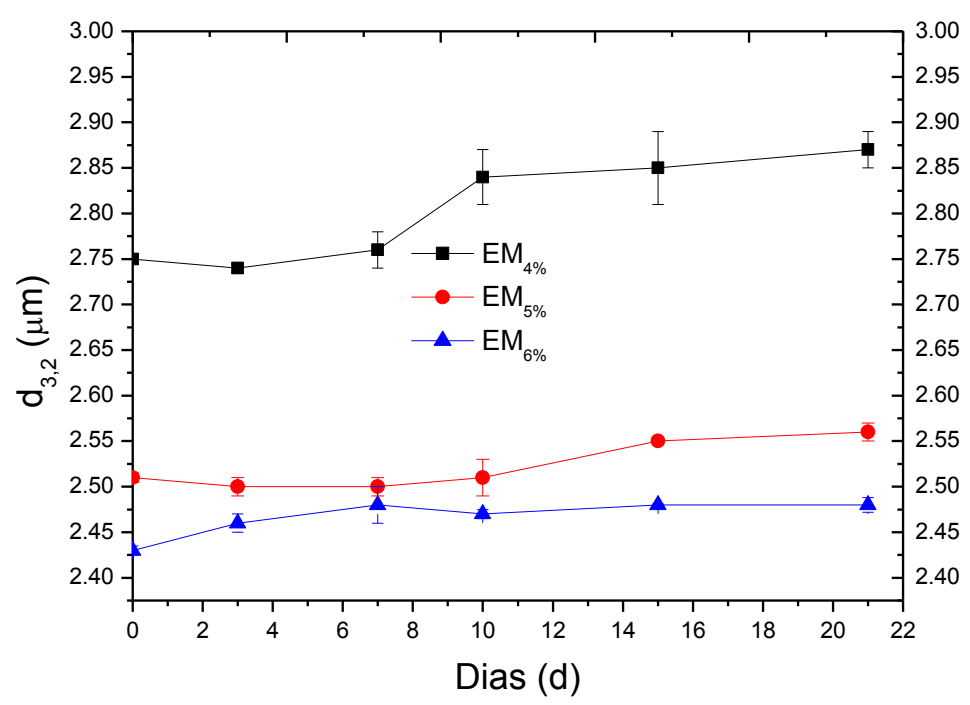

Figura 5. Cambios en el diámetro volumétrico superficial medio de gota $\left(d_{3,2}\right)$ de las EM con el tiempo de almacenamiento.

Los procesos de desestabilización que las EM pueden sufrir son variados; por ejemplo, la interfase externa de la gota puede coalecer con una o más gotas de EM; las gotas internas de agua pueden ser expulsadas secuencialmente a partir de las gotas de las EM; la contracción gradual de las gotas internas es posible debido a un gradiente osmótico entre las fases acuosas interna y continua, cuando el transporte de masa neta de agua se produce de la fase interna a la fase continua externa a través de la película de aceite que actúa como una "membrana semipermeable"; y por el contrario, cuando el gradiente osmótico actúa en la dirección opuesta, difusión de agua a partir de la fase continua a través de la película de aceite hacia las gotas acuosas encapsuladas producirá hinchamiento de las gotas internas (Hernández-Marín y col., 2013). Sin embargo, se ha establecido que combinaciones adecuadas de emulsionantes en las fases interna y externa tienen efectos benéficos sobre la estabilidad de las EM (Garti, 1997). El uso óptimo de emulsionantes en la formulación de EM depende de sus propiedades reológicas interfaciales (Maldonado-Valderrama y Rodríguez-Patiño, 2010). Se ha encontrado una correlación positiva entre la estabilidad de la emulsión contra la coalescencia de las gotas y la viscosidad de corte superficial en emulsiones aceite-en-agua (Dickinson y col., 1988). Además, películas de proteínas altamente viscoelásticas tienden a amortiguar fluctuaciones superficiales, inhibiendo de este modo el mecanismo responsable de la ruptura de la película (Dickinson, 1992). Los 
resultados de este trabajo tienden a confirmar que la estabilidad de las EM estuvo estrechamente relacionada con las propiedades reológicas de las películas MGGL.

\subsubsection{Propiedades reológicas oscilatorias de las EM}

Las pruebas oscilatorias dinámicas de corte de pequeña amplitud son una herramienta muy útil para obtener información acerca de la estructura microscópica de materiales viscoelásticos como emulsiones, proporcionando los valores de los módulos de almacenamiento $\left(G^{\prime}\right)$ y de pérdida $\left(G^{\prime}\right.$ '). $G^{\prime}$ ' es proporcional a la magnitud del componente elástico del sistema, y $\mathrm{G}^{\prime \prime}$ es proporcional a la magnitud del componente viscoso del sistema (Wulff-Pérez y col., 2011). Todas las EM preparadas con diferentes concentraciones de MGGL, mostraron incrementos en G' y G' como una función de la frecuencia, exhibiendo valores de G' mayores a aquellos de G'" sobre todo el intervalo de frecuencia estudiada (Fig. 6). Ambos, G' y G', fueron dependientes de la frecuencia, aunque esta dependencia disminuyó a medida que aumentó la concentración de MGGL. El tipo de comportamiento que se muestra en la figura 6 es típico de emulsiones concentradas teniendo una estructura de gel débil, que surge de flóculos mantenidos juntos fuertemente mediante puentes poliméricos, pero que son susceptibles a reorganización durante el almacenamiento y en presencia de campos de corte (Dickinson y Pawlowsky, 1996; Barnes, 2004). Los valores de G' y G' incrementaron al aumentar la concentración de MGGL y este comportamiento parece estar estrechamente interconectado con los valores $\mathrm{d}_{3,2}$ mostrados por las EM. Menores valores de $\mathrm{d}_{3,2}$ implican mayor número de gotas de EM por unidad de volumen y una estructura de flóculos con mayor interconectividad. 


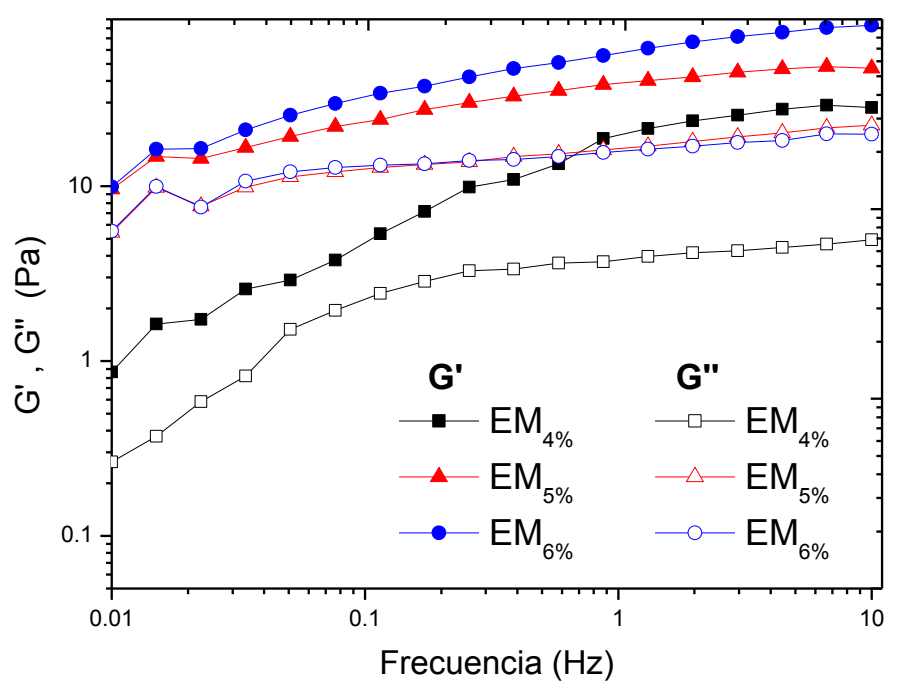

Figura 6. Evolución de los módulos de almacenamiento (G') y pérdida (G') de las EM durante barridos de frecuencia a $0.2 \%$ de deformación. 


\section{CONCLUSIONES}

Los resultados de reología interfacial indicaron que concentraciones mayores de MGGL produjeron películas con mayor módulo elástico instantáneo interfacial $\left(\mathrm{E}_{0}\right): 0.4 \mathrm{mN} / \mathrm{m}$ para $4 \% ; 0.8 \mathrm{mN} / \mathrm{m}$ para $5 \%$ y $1.2 \mathrm{mN} / \mathrm{m}$ para $6 \%$, y mayor viscosidad interfacial $\left(\mathrm{n}_{\mathrm{N}}\right)$ : $1197.0 \mathrm{mNs} / \mathrm{m}$ para $4 \%, 4456.3 \mathrm{mNs} / \mathrm{m}$ para $5 \%$ y $4633.2 \mathrm{mNs} / \mathrm{m}$ para $6 \%$. Cuando se adicionó PGPR a la fase oleosa, las moléculas de MGGL fueron desplazadas de la interfase en cierta medida, resultando en una película interfacial debilitada, pero todavía mecánicamente fuerte. Se encontró una estrecha interrelación entre la estabilidad de las emulsiones múltiples y las propiedades reológicas interfaciales de las películas de MGGL + PGPR. Las emulsiones múltiples estabilizadas por MGGL en diferentes concentraciones mostraron propiedades viscoelásticas dependientes de la frecuencia, donde el módulo de almacenamiento tuvo valores más altos que el módulo de pérdida sobre toda el rango de frecuencias estudiado. Este comportamiento es característico de estructuras de gel débil que surgen de puentes poliméricos entre flóculos. Concentraciones mayores de MGGL produjeron módulos viscoelásticos mayores y menor dependencia de la frecuencia, lo que sugiere una estrecha correspondencia con el tamaño de gota de las emulsiones múltiples. 


\section{REFERENCIAS}

AOAC. (1995). Association of Official Analytical Chemists, 16th edn. Association of Oficial Analytical Chemists, Arlington.

Barnes, H.A. (2004). The rheology of emulsions. En: Emulsions: Structure stability and interactions, Interface Science and Technology Vol. 4, (D.N. Petsev, ed.), Pp. 721-759. Elsevier B.V., Amsterdam, Holanda.

Benichou A, Aserin A, Garti N. (2004). Double emulsions stabilized with hybrids of natural polymers for entrapment and slow release of active matters. Advanced. Colloid Interface $108-9,29-41$.

Beverung, C.J., Radke, C.J. y Blanch, H.W. (1999). Protein adsorption at the oil/water interface: characterization of adsorption kinetics by dynamic interfacial tension measurements. Biophysical Chemistry 81, 59-80.

Bezelgues, J.B., Morgan, F., Palomo, G., Crosset-Perrotin, L. y Ducret, P. (2009). Short communication: Milk fat globule membrane as a potential delivery system for liposoluble nutrients. Journal of Dairy Science 92, 2524-2528.

Burgess, D. J. y Sahin, N. (1997). Interfacial rheological and tension properties of protein films. Colloid Interface Science 189, 74-82.

Corredig, M. y Dalgleish, D.G. (1998). Buttermilk properties in emulsions with soybean oil as affected by fat globule membrane-derived proteins. Journal of Food Science 63, 476-480.

Cournarie, F., Savelli, M.P., Rosilio, W., Bretez, F., Vauthier, C., Grossiord, J.L. y Seiller, M. (2004). Insulin-loaded W/O/W multiple emulsions: comparison of the performances of systems prepared with medium-chain-triglycerides and fish oil. European Journal Pharmaceutics and Biopharmaceutics 58(3),477-82.

Crook, T., Tinklenberg, J., Yesavage, J., Petrie, W., Nunzi, M. y Massari, D. (1991). Effects of phosphatidylserine in age-associated memory impairment. Neurology 41, 644-649.

Danthine, S., Blecker, C., Paquot, M., Innocente, N. y Deroanne, C. (2000). Progress in milk fat globule membrane research: A review. Lait 80, 209-222.

Dewettinck, K., Rombaut, R., Thienpont, N., Le, T. T., Messens, K.y Van Camp, J. (2008). Nutritional and technological aspects of milk fat globule membrane material. International Dairy Journal 18, 436-457. 
Dickinson, E. (1991). Competitive adsorption and protein-surfactant interactions in oil-in-water emulsions. En: Microemulsions and Emulsions in Foods, (M. El-Nokaly y D. Cornell, eds.), Pp. 114-128. American Chemical Society, Washington, DC.

Dickinson, E. (1992). Interfacial interactions and the stability of oil-in-water emulsions. Pure and Applied Chemistry 64, 1721-1724.

Dickinson, E. y Euston, S.R. (1991). Stability of food emulsions containing both protein and polysaccharide. En: Food Polymers, Gels and Colloids. Dickinson, E. (ed.). Pp. 132-146. Royal Society of Chemistry, Cambridge.

Dickinson, E. y Pawlowsly, K. (1996). Rheology as a probe of protein-polysaccharide interactions in oil-in-water emulsions. En: Gums and Stabilizers for the Food Industry 8, (G.O. Phillips, P.A. Williams y D.J. Wedlock, eds.), Pp. 181-191. IRL Press, Oxford, RU.

Dickinson, E., Murray, B.S. y Stainsby, G. (1988). Coalescence stability of emulsion sized droplets at a planar oil-water interface and the relationship to protein film surface rheology. Journal of the Chemical Society, Faraday Transactions 1: Physical Chemistry in Condensed Phases 94, 871-883.

Doxastakis, G. y Sherman, P. (1983). The influence of the interaction of mono- and diglycerides with milk proteins on the rheology and stability of food emulsions (corn-in-oilwater emulsions). En: Instrumental Analysis of Foods Vol. 2. Dairy Products; Food Quality; Food Composition, (G. Charalambous y G. Inglett, eds.), Pp. 219-285. Academic Press, Nueva York, NY.

Espinosa-Andrews, H., Lobato-Calleros, C., Loeza-Corte, J.M., Beristain, C.I., Rodríguez-Huezo, M.E. y Vernon-Carter, E.J. (2008). Quantification of the composition of gum arabicchitosan coacervate by HLPC. Revista Mexicana de Ingeniería Química 7, 293-298.

Fechner, A., Knoth, A., Scherze, I. y Muschiolik, G. (2007). Stability and release properties of double-emulsions stabilised by caseinate-dextran conjugates. Food Hydrocolloids 21(5-6), 943-52.

Fong, B.Y., Norris, C.S. y MacGibbon, A.K.H. (2007). Protein and lipid composition of bovine milk-fat-globule membrane. International Dairy Journal 17, 275-288.

Ganzevles, R.A., Zinoviadou, K., van Vliet, T., Cohen-Stuart, M.A. y de Jongh, H.H.J. (2006). Modulating surface rheology by electrostatic protein/polysaccharide interactions. Langmuir 22, 10089-10096. 
Garti, N. (1997). Progress in stabilization and transport phenomena of double emulsions in food applications. Lebensmittel Wissenschaft und Technologie 30, 222-235.

Garti, N. y Bisperink, C. (1998). Double emulsions: progress and applications. Current Opinion Colloid In 3(6), 657-667.

He, Q., Zhang, Y., Lu, G., Miller, R., Mohwald, H. y Li, J. (2008). Dynamic adsorption and characterization of phospholipid and mixed phospholipid/protein layers at liquid/liquid interfaces. Advances in Colloid and Interface Science 140, 67-76.

Henry, J.V.L., Fryer, P.J., Frith, W.J. y Norton, I.T. (2010). The influence of phospholipids and food proteins on the size and stability of model submicron emulsions. Food Hydrocolloids 24,6671 .

Hernàndez -Marin, N.Y., Lobato-Calleros, C. y Vernon-Carter, E.J. (2013). Stability and rheology of water-in-oil-in-water multiple emulsions made with protein-polysaccharide soluble complexes. Journal of Food Engineering 119, 181-187.

Jensen, R.G. (2002). The composition of bovine milk lipids: January 1995 to December 2000. Journal of Dairy Science 85, 295-350.

Kanno, C. (1989). Emulsifying properties of bovine milk fat globule membrane in milk fat emulsion: conditions for the reconstitution of milk fat globules. Journal of Food Science $56,1219-1223$.

Kanno, C. y Kim, D.H. (1990). A simple procedure for the preparation of bovine milk fat globule membrane and a comparison of its composition enzymatic activities, and electrophoresis properties with those prepared by other methods. Agricultural and Biological Chemistry Tokyo 54, 2845-2854.

Kitchener, J.A. y Musselwhite, P.R. (1969). The theory of stability of emulsions. En Emulsion Science, (P. Sherman, ed.), Pp. 77130. Academic Press, Londres, RU.

Koopman, J., Turkish, V. y Monto, A. (1985). Infant formula and gastrointestinal illness. American Journal of Public Health 75, 477-480.

Krägel, J., Derkatch, S.R. y Miller, R. (2008). Interfacial shear rheology of protein-surfactant layers. Advances in Colloid and Interface Science 144, 38-53.

Kukizaki, M. y Goto, M. (2007). Preparation and evaluation of uniformly sized solid lipid microcapsules using membrane emulsification. Colloid Surface A 293(1-3), 87-94. 
Lee, J.J., Park, I.B., Cho, Y.H., Huh, C.S., Baek, Y.J. y Park J. (2004). Whey protein-based IgY microcapsules prepared by multiple emulsification and heat gelation. Food Science Biotechnology 13(4), 494-497.

Lobato-Calleros, C., Aguirre-Mandujano, E., Vernon-Carter, E.J. y Sanchez-Garcia, J. (2000). Viscoelastic properties of white fresh cheese filled with sodium caseinate. Journal of Texture Studies 31, 379-390.

Lobato-Calleros, C., Recillas-Mota, M.T., Espinosa-Solares, T., Alvarez-Ramirez, J. y VernonCarter, E.J. (2009). Microstructural and rheological properties of low-fat stirred yoghurts made with skim milk and multiple emulsions. Journal of Texture Studies 40, 657-675.

Lòpez C. (2011). Milk fat globules enveloped by their biological membrane: unique colloidal essemblies with a specific composition and structure. Current Opinion in Colloid and interface Science. $\mathrm{xxx}, \mathrm{xxx}-\mathrm{xx}$.

Maldonado-Valderrama, J. y Rodríguez-Patino, J.M. (2010). Interfacial rheology of protein surfactant mixtures. Current Opinion in Colloid \& Interface Science 15, 271-282.

Martin, A., Bos, M., Cohen, M. S. y van Vliet, T. (2002). Stress-strain curves of adsorbed protein layers at the air/water interface measured with surface shear rheology. Langmuir, 18, $1238-1243$.

McClements, D. J., Decker, E. A. y Weiss, J. (2007). Emulsion-based delivery systems for lipophilic bioactive components. Journal of Food Science 72, 109-124.

McClements, D.J. y Li, Y. (2010). Structured emulsion-based delivery systems: Controlling the digestion and release of lipophilic food components. Advanced Colloids and Interfaces $159,213-228$.

Menard O., Ahmad S., Rousseau F., Briard-Bion V., Gaucheron F. y Lopez C. (2010). Buffalo vs cow milk fat globules: size distribution, zeta-potential, composition in total fatty acids and in polar lipids from the milk fat globule membrane. Food Chemistry 120, 544-551.

Morin, P., Jimenez-Flores, R. y Pouliot, Y. (2004). Effect of temperature and pore size on the fractionation of fresh and reconstituted buttermilk by microfiltration. Journal of Dairy Science 87, 267-273.

Morin, P., Pouliot, Y. y Jimenez-Flores, R. (2006). A comparative study of the fractionation of regular buttermilk and whey buttermilk by microfiltration. Journal of Food Engineering 77, 521-528. 
Murray, B (2011). Rheological properties of protein films. Current Opinion in Colloid \& Interface Science 16, 27-35.

Murray, B. y Dickinson, E. (1996). Interfacial rheology and the dynamic properties of adsorbed films of food proteins and surfactants. Food Science and Technology International 2-3, $131-145$.

Nalto, H.K. (1975). Modification of the Fiske and SubbaRow method for total phospholipid in serum. Clinical Chemistry 21, 1454-1456.

Onuki, Y., Morishita, M., Watanabe, H., Chiba, Y., Tokiwa, S., Takayama, K. y Nagai, T. (2003). Improved insulin enteral delivery using water-in-oil-in-water multiple emulsion incorporating highly purified docosahexaenoic acid. Stp Pharma Science 13(4), 231-235.

Parodi, P.W. (2001). Cow's milk components with anti-cancer potential. Australian Journal of Dairy Technology 56, 65-73.

Pérez-Orozco, J.P., Barrios-Salgado, E., Román-Guerrero, A. y Pedroza-Islas, R. (2011). Interaction of mesquite gum-chitosan at the interface and its influence on the stability of multiple emulsions W/O/W. Revista Mexicana de Ingeniería Química 10, 487-499.

Pérez-Orozco, J.P., Beristain, C.I., Espinosa-Paredes, G., Lobato-Calleros, C. y Vernon-Carter, E.J. (2004). Interfacial shear rheology of interacting carbohydrate polyelectrolytes at the water-oil interface using an adapted conventional rheometer. Carbohydrate Polymers 57, 45-54.

Ramírez-Santiago, C., Lobato-Calleros, C., Espinosa-Andrews, H., Vernon-Carter, E.J. (2012). Viscoelastic properties and overall sensory acceptability of reduced-fat Petit-Suisse cheese made by replacing milk fat with complex coacervate. Dairy Science and Technology 92, 383-398.

Rietberg, M., Rousseau, D. y Duizer, L. (2012). Sensory evaluation of sodium chloride-containing water-in-oil emulsions. Journal of Agricultural and Food Chemistry 60, 4005-4011.

Rodriguez-Huezo, M.E., Pedroza-Islas, R., Prado-Barragán, L.A., Beristain, C.I. y Vernon-Carter, E.J. (2004). Microencapsulation by spray drying of multiple emulsions containing carotenoids. Journal of Food Science 69(7), E351-359.

Rodríguez-Patino, J. M. y Rodríguez-Niño, M. R. (1999). Interfacial characteristics of food emulsifiers (proteins and lipids) at the air-water interface. Colloids and Surfaces B: Biointerfaces 15, 235-252. 
Rodríguez-Patino, J.M., Carrera-Sánchez, C., Rodríguez-Niño, M.R. y Cejudo Fernández, M. (2001). Structural and dynamic properties of milk proteins spread at the air-water interface. Journal of Colloid and Interface Science 242, 141-151.

Roesch, R.R., Rincon, A. y Corredig, M. (2004). Emulsifying properties of fractions prepared from commercial buttermilk by microfiltration. Journal of Dairy Science 87,4080-4087.

Román-Guerrero, A., Orozco-Villafuerte, J., Perez-Orozco, J.P., Cruz-Sosa, F, Jimenez-Alvarado, R. y Vernon-Carter, E.J. (2009). Application and evaluation of mesquite gum and its fractions as interfacial film formers and emulsifiers of orange peel-oil. Food Hydrocolloids 23,708713 .

Rombaut, R., Dejonckheere, V. y Dewettinck, K. (2007). Filtration of milk fat globule membrane fragments from acid buttermilk cheese whey. Journal of Dairy Science, 90, 1662-1673.

Roth, S., Murray, B.S. y Dickinson, E. (2000). Interfacial shear rheology of aged and heat-treated b-lactoglobulin films: displacement by nonionic surfactant. Journal of Agricultural and Food Chemistry 48, 1491-1497.

Ruíz-Ramos, J.O., Pérez-Orozco, J.P., Báez-González, J.G., Bósquez-Molina, E., Pérez-Alonso, C. y Vernon-Carter, E.J. (2006). Interrelationship between the viscoelastic properties and effective moisture diffusivity of emulsions with the water vapor permeability of edible films stabilized by mesquite gum-chitosan complexes. Carbohydrate Polymers 64, 355363.

Sánchez-González, J., Cabrerizo-Vílchiz, M.A. y Gálvez-Ruíz, M.J. (1999). Evaluation of the interactions between lipids and $\beta$-globulin protein at the air-liquid interface. Colloids and Surfaces B: Biointerfaces, 12, 123-138.

Sánchez-Juanes, F., Alonso, J.M., Zancada, L. y Hueso, P. (2009). Distribution and fatty acid content of phospholipids from bovine milk and bovine milk fat globule membranes. International Dairy Journal 19, 273-278.

Sapei, L., Naqvi, M. A., Rousseau, D. (2012). Stability and release properties of double emulsions for food applications. Food Hydrocolloids 27, 316-323.

Schmitt, C. y Turgeon, S.L. (2011). Protein/polysaccharide complexes and coacervates in food systems. Advances in Colloid and Interface Science 167, 63-70.

Singh, H. (2006). The milk fat globule membrane. A biophysical system for food applications. Current Opinion in Colloid and Interface Science 11, 154-163. 
Spitsberg, V.L. (2005). Invited review: Bovine milk fat globule membrane as a potential nutraceutical. Journal of Dairy Science 88, 2289-2294.

Su, J.H., Flanagan, J., Hemar, Y. y Singh, H. (2006). Synergistic effects of polyglycerol ester of polyricinoleic acid and sodium caseinate on the stabilisation of water-oil-water emulsions. Food Hydrocolloids 20(2-3), 261-268.

Thompson, A.K. y Singh, H. (2006). Preparation of liposomes from milk fat globule membrane phospholipids using a microfluidizer. Journal of Dairy Science 89, 410-419.

Van Bockstaele, F., De Leyn, I., Eeckhout, M. y Dewettinck, K. (2011). Non-linear creep recovery measurements as a tool for evaluating the viscoelastic properties of wheat flour dough. Journal of Food Engineering 107, 50-59.

Vanderghem, C., Bodson, P., Danthine, S., Paquot, M., Deroanne, C. y Blecker, C. (2010). Milk fat globule membrane and buttermilks: from composition to valorization. Biotechnology, Agronomy, Society and Environment 14, 485-500.

Waninge, R., Walstra, P., Bastiaans, J., Nieuwenhuijse, H., Nylander, T., Paulsson, M. y Bergenstahl, B. (2005). Competitive adsorption between $\beta$-casein or $\beta$-lactoglobulin and model milk membrane lipids at oil-water interfaces. Journal of Agricultural and Food Chemistry 53, 716-724.

Weiss, J, Scherze, I. y Muschiolik, G. (2005). Polysaccharide gel with multiple emulsion. Food Hydrocolloids 19(3), 605-615.

Wulff-Pérez, M., Torcello-Gómez, A., Martin Rodríguez, A., Gálvez-Ruiz, M.J. y de Vicente, J. (2011). Bulk and interfacial viscoelasticity in concentrated emulsions: The role of the surfactant. Food Hydrocolloids 25, 677-686.

Ye, A., Singh, H., Taylor, M.W. y Anema, S. (2002). Characterization of protein components of natural and heat-treated milk fat globule membranes. International Dairy Journal 12, 393 402. 
10. Anexo

Publicacion 


\title{
Revista Mexicana de Ingeniería Química
}

Vol. 12, No. 3 (2013) 425-436

Vol. 12, No. $3(2013) 425-436$

STABILITY OF WATER-IN-OIL-IN-WATER MULTIPLE EMULSIONS: INFLUENCE
OF THE INTERFACIAL PROPERTIES OF MILK FAT GLOBULE MEMBRANE

\section{ESTABILIDAD DE EMULSIONES AGUA-EN-ACEITE-EN-AGUA: INFLUENCIA DE LAS PROPIEDADES INTERFACIALES DE LA MEMBRANA DEL GLOBULO DE GRASA LÁCTEA}

\author{
J.G. Dzul-Cauich' ${ }^{1}$, C. Lobato-Calleros ${ }^{2 *}$, J.P. Perez-Orozco ${ }^{3}$, J. Alvarez-Ramirez ${ }^{4}$ y E.J. Vernon-Carter ${ }^{4}$ \\ ${ }^{1}$ Departamento de Biotecnología, Universidad Autónoma Metropolitana-Iztapalapa, San Rafael Atlixco 186, \\ Vicentina, México, D.E. 09340, Méxica. \\ ${ }^{2}$ Departamento de Preparatoria Agrícola, Universidad Autónoma Chapingo, Km 385 Carretera México-Texcoco, \\ 56227 Texcoco, México. \\ ${ }^{3}$ Inst ituto Tecnológico de Zacatepec, Departamento de Ingeniería Química y Bioquímica, Calzada Tecnológico \\ No.27, Col Centro, Zacatepec, Morelos 62780, Méxica \\ ${ }^{4}$ Departamento de Ingeniería de Procesos e Hidráulica, Universidad Autónoma Metropolitana-Iztapalapa, San \\ Rafael Arlixco 186, Vicentina, México, D.F. 09340, Méxica.
}

Received October 30, 2013; Accepted November 5, 2013

\begin{abstract}
The interfacial shear viscosity $\left(\eta^{i n}\right)$ and the creep compliance-time $(J(t))$ behavior of milk fat globule membrane (MFGM) films $(4,5$ and $6 \%$ w/w) formed at the water-oil interface were evaluated. Films with higher MFGM concentration displayed higher $\eta^{\text {in }}$ and interfacial viscoelastic properties. When esters of polyglycerol and polyriciniolate fatty acids (PGPR) were added to the oil phase, a competitive adsorption at the interface took place between PGPR and MFGM which caused a decrease in the interfacial viscoelastic properties of the films. The change in the rheological behavior of the films suggests that their interfacial structure was determined by complex interactions between the MFGM and PGPR molecules. Water-in-oil-in-water multiple emulsions (ME) with smaller surface-volume droplet size ( $\left.d_{3,2}\right)$, greater stability, and higher storage (G') and loss (G') moduli were obtained when higher MFGM concentrations were used in the outer aqueous phase.
\end{abstract}

Keywords : milk fat globule membrane, esters of polyglycerol polyriciniolate fatty acids, multiple emulsions stability, bulk and interfacial rheological properties.

\begin{abstract}
Resumen
La viscosidad de corte interfacial $\left(\eta^{\text {in }}\right)$ y el comportamiento creep compliance-tiempo $(J(t))$ de peliculas de membrana de glóbulo de grasa láctea (MFGM) $(4,5$ y $6 \%$ p'p) formadas en la interfase aceite-agua fueron evaluados. Las películas con mayor concentración de MFGM mostraron mayores $\eta^{\text {int }}$ y propiedades viscoelásticas interfaciales. Cuando se adicionaron ésteres de ácidos grasos de poliglicerol y poliricinoleato (PGPR) a la fase oleosa, una adsorción competitiva tomó lugar en la interfase entre PGPR y MFGM, lo cual causó decremento en las propiedades viscoelásticas interfaciales de las películas. El cambio en el comportamiento reologico de las películas sugiere que su estructura interfacial fue determinada por interacciones complejas entre las moléculas de MFGM y PGPR. Emulsiones múltiples agua-en-aceite-en-agua con gotas de menor diametro volumétrico superficial, mayor estabilidad y mas altos módulos de almacenamiento $\left(G^{\prime}\right)$ y de pérdida $\left(G^{\prime \prime}\right)$, se obtuvieron cuando se utilizaron concentraciones más altas de MGGL en la fase acuosa externa.
\end{abstract}

Palabras clave: membrana del glóbulo de grasa láctea, ésteres de ácidos grasos de poliglicerol y poliricinioleato, estabilidad de las emulsiones multiples, propiedades reologicas interfaciales.

\footnotetext{
"Corresponding withar. E-mait: consuel obatodyahoo, con Tel. (52)5959521617, Fax(52)5959521618
} 


\section{Introduction}

Milk fat exists as an emulsion of tiny, spherical oil globules dispersed in the whey (Jensen, 2002). The diameter of the milk fat globules ranges from $(0.2$ $15 \mu \mathrm{m})$ and they are surrounded by a 4 to $10-\mathrm{nm}$ multilayer membrane (MFGM) composed primarily of triglycerides, proteins, and phospholipids (Danthine et al., 2000; Singh, 2006). The MFGM ensures structural integrity, protection and stability of the milk fat in the aqueous phase (Ye et al.. 2002; Bezelgues et al., 2009). Several studies have indicated that some of the components of MFGM have healthenhancing functions, in addition to MFGM having excellent emulsification properties (Kanno, 1989; Corredig and Dalgleish, 1998; Roesch et al., 2004 Thompson and Singh, 2006; Singh, 2006; Bezelgues ef al., 2009). Both phospholipids and some proteins have shown to have inhibitory activity against breast cancer, and reducing the number of colon tumors (Spitsberg. 2005: Singh, 2006). Also phospholipids have shown beneficial effects against development of Alzheimer's disease (Parodi, 2001; Spitsberg, 2005), liver protection (Koopman et al., 1985), and memory improvement (Crook et al., 1991).

In milk, the phospholipid-protein layer acts as a surfactant to prevent coalescence and flocculation of the fat globules in their aqueous environment (Bezelgues et al., 2009). Mixtures of proteins and phospholipids are not only met in nature such as in biomembranes but also are widely used for the stabilization of emulsions and foams in food industry (Henry et al., 2010). Thus, the study of the adsorption behavior and interfacial rheology of mixed phospholipid/protein layers shed knowledge that allow to gain understanding regarding interfacial activity and emulsion stability (He et al., 2008).

The unique properties of MFGM have led to research into developing technologies for the isolation and separation of MFGM-enriched material from milk. MFGM-enriched material could potentially be incorporated into food emulsions, and could result in new functional foods and nutraceuticals. MFGM is released into the aqueous phase during cream chuming (destabilization of milk fat globules) for obtaining butter, resulting in a by-product named buttermilk. Buttermilk is low cost and available in large quantities but has been considered for many years as a low value product. However, over the last two decades it has gained considerable attention due to its specific composition in proteins and polar lipids sourced from the MFGM (Vanderghem et al., 2010).
On the other hand there is a need for edible delivery systems to encapsulate, protect and release bioactive and functional lipophilic and hydrophilic constituents within the food and pharmaceutical industries. In this sense multiple emulsions (ME) could be used for a number of purposes including targeting the delivery of bioactive components within the gastrointestinal tract, and designing food matrices that delay lipid digestion (McClements and Li, 2010). The droplets in water-in-oil-in-water ME used in the food and pharmaceutical industries may be stabilized by a variety of different emulsifiers, including small molecule surfactants, biopolymers and phospholipids. In particular, it is important that these delivery systems can be fabricated from food-grade ingredients using economically viable processing operations, and that they are robust enough to remain stable throughout their application in foods.

The objectives of this work were to: (a) determine the interfacial shear viscosity and interfacial viscoelastic properties of adsorbed films of MFGM (b) evaluate the effect of the competitive adsorption between MFGM and esters of polyglycerol and polyriciniolate fatty acids (PGPR) on the viscoelastic properties of the films; and (c) evaluate the influence of the interfacial MFGM/PGPR films on the stability and bulk rheological properties of the water-in-oil-inwater ME.

\section{Materials and methods}

\subsection{Materials}

Canola oil (CO; Capullog); Unilever de Mexico, S.A. de C.V.); carboxy methy lcellulose (CMC; CMCR CEROL 50 000; Grupo Dermet, S.A. de C.V.) lipophilic emulsifier (PGPR; Grinsted(B) PGPR 90, esters of polyglycerol and polyriciniolate fatty acids; Danisco Mexico, S.A. de C.V.); hydrochloric acid, sodium hydroxide, chloroform, methanol, perchloric acid, ammonium molybdate, sodium bisulfite, sodium sulfite, and monopotassium phosphate (J.T. Baker, S.A de C.V.): 1-amino-2-naphtol-4-sulfonic acid (Alta Pureza Maquiladora S.A de C.V.) were all purchased in Mexico City, Mexico. Distilled deionized water (ddw) was used in all the experiments.

\subsection{Isolation of $M F G M$}

MFGM was isotated from fresh raw cream following the procedure described by Fong et al. (2007) with slight modifications. Ten $\mathrm{L}$ of fresh raw cream $(40 \mathrm{~g}$ of 
fat per $100 \mathrm{~g}$; Planta Lechera, Universidad Autonoma Chapingo, Texcoco, State of Mexico, Mexico) was used in each of the experimental runs. The cream ( 30 $\pm 1^{\circ} \mathrm{C}$ ) was suspended in washing solution (ddw at $38 \pm 1^{\circ} \mathrm{C}$ ) in a proportion of $1 \mathrm{~L}$ of cream per $3 \mathrm{~L}$ of ddw) applying gentle agitation $(880 \mathrm{rpm}, 15 \mathrm{~min})$ with a mechanical mixer (CAFRAMO model RZRI, Cole-Parmer, Vernon Hills, II, USA). The cream was subsequently separated with a bench-top cream separator. This washing step was repeated thrice. After being refrigerated overnight at $4 \pm 1^{\circ} \mathrm{C}$, the washed cream was churned using a KitchenAid mixer (KSMC5OS KitchenAid Inc., St. Joseph, Michigan, USA) operated at $750 \mathrm{~mm}$ at $10^{\circ} \mathrm{C}$ until butter and buttermilk were obtained. Buttermilk was collected by filtration through 2 layers of cheesecloth, which was used to retain minute butter granules. The $\mathrm{pH}$ of the buttermilk was adjusted at 4.8 with hydrochloric acid (IM) for inducing MFGM precipitation. The resulting slurry was centrifuged in glass tubes with a laboratory centrifuge (Sorvall RC-5B; GMI Inc., Ramsey, MN, USA) at $10000 \mathrm{rpm}$ for $30 \mathrm{~min}$, in order to separate the insoluble MFGM. The $\mathrm{pH}$ of the MFGM suspension was adjusted at 6.8 using sodium hydroxide (IM). The pooled MGFM suspension was freeze dried in a Lyph Lock (1) 4.5 freeze dryer (Labconco Corporation, MO, USA) and the resulting powder was stored at $-20^{\circ} \mathrm{C}$ until required for use.

\subsection{Determination of total protein, total lipid and phospholipids of MFGM}

The total protein content of the freeze-dried MFGM was determined by the Kjeldahl method (AOAC, 1995) using 6.38 as the conversion factor.

Lipids were extracted from MFGM following the procedure described by Sánchez-Juanes et al. (2009) with slight modifications. MFGM powder ( $1 \mathrm{~g}$ ) was dissolved in $10 \mathrm{~mL}$ of chloroform/methanol $(1: 1 \mathrm{v} / \mathrm{v})$, stimed overnight at $4{ }^{\circ} \mathrm{C}$, and centrifuged at $1700 \mathrm{rpm}$ for $10 \mathrm{~min}$ at $4^{\circ} \mathrm{C}$. The pellet was re-homogenized in $10 \mathrm{~mL}$ of chloroform/methanol $(2: 1 \mathrm{v} / \mathrm{v})$, stimed for $45 \mathrm{~min}$ at $4{ }^{\circ} \mathrm{C}$ and centrifuged as described above. The new pellet was re-homogenized in 10 $\mathrm{mL}$ of chloroform/methanol $(1: 2 \mathrm{v} / \mathrm{v})$ and stirred and centrifuged as above. The combined supernatants were reduced to one quarter of the original volume by drying at $40^{\circ} \mathrm{C}$ in an owen (model HS-33 Rios Rocha, Mexico City, Mexico), kept overnight at $-20^{\circ} \mathrm{C}$, and centrifuged at $1700 \mathrm{rpm}$ for $10 \mathrm{~min}$ at $4^{\circ} \mathrm{C}$ to remove insoluble material. The resulting extract was put into a Petri dish, dried in an oven at $400^{\circ} \mathrm{C}$ for $24 \mathrm{~h}$.
Afterwards the Petri dish was put in a desiccator with $\mathrm{CaCl}_{2}$ as desiccant for $24 \mathrm{~h}$, and total lipids (TL) were determined gravimetrically.

TL $(0.15$ g) were re-dissolved with chloroform/methanol $(1: 2 \mathrm{v} / \mathrm{v})$ and diluted to $10 \mathrm{~mL}$. and $1 \mathrm{~mL}$ sample was taken and dried by evaporation $\left(40{ }^{\circ} \mathrm{C}\right)$. Total phospholipids content (TPC) was determined based on the procedure described by Nalto (1975), with modifications. The dried sample was added with $0.8 \mathrm{~mL}$ of perchloric acid $(72 \% \mathrm{v} / \mathrm{v})$ in a $15 \times 150 \mathrm{~mm}$ graduated glass tube, which was placed in a sand bath at $200^{\circ} \mathrm{C}$ for $30 \mathrm{~min}$, and cooled to room temperature $\left(20 \pm 2^{\circ} \mathrm{C}\right)$. Approximately $6 \mathrm{~mL}$ of ddw $+0.5 \mathrm{~mL}$ of ammonium molybdate reagent $(5 \% \mathrm{w} / \mathrm{v})$ were added and mixed, followed by the addition of 0.4 $\mathrm{mL}$ of reducing reagent $(27.2 \mathrm{~g}$ of sodium bisulfite + $6 \mathrm{~g}$ of sodium sulfite $+0.5 \mathrm{~g}$ of 1 -amino-2-naphtol4-sulfonic acid, diluted to $250 \mathrm{~mL}$ ). The content of the tube was diluted to $10 \mathrm{~mL}$ with ddw. Afterwards, the mixture was left to react for $20 \mathrm{~min}$ and the absorbance read in a spectrophotometer (Spectronics Genesys 5 UV/Vis, Spectronic Unicam, Rochester, NY, USA) at $660 \mathrm{~nm}$. The spectrophotometer was zeroed with a reagent blank ( $0.8 \mathrm{~mL}$ perchloric acid). Calibration was done using $0.1 \mathrm{~mL}$ of a standard solution $\left(\mathrm{KH}_{2} \mathrm{PO}_{4}, 0.5 \mathrm{mg} \mathrm{mL}{ }^{-1}=11.38 \mu \mathrm{g}\right.$ of $\mathrm{P}+$ $0.8 \mathrm{~mL}$ of perchloric acid). TPC was calculated using the equation 1 .

$$
T P C(m g / L)=\left(A_{s} / A_{s d d}\right) \times\left[P_{s d} \times\left(V_{s d} / V_{s}\right)\right] \times 25 \text { (1) }
$$

Where TPC $=$ total phospholipids content $\left(\mathrm{mg} \cdot \mathrm{L}^{-1}\right)$; As = absorbance of sample: $\mathrm{A}_{\text {nd }}=$ absorbance of standard solution; $\mathrm{P}_{s d d}=$ phosphorous in standard solution ( $\left.\mathrm{mg} \mathrm{L}^{-1}\right) ; V_{s d}=$ volume of standard solution $(\mathrm{mL}) ; V_{s}=$ volume of sample $(\mathrm{mL})$; and $25=$ factor for converting phosphorous (mg) to phospholipids (mg).

\subsection{Interfacial rheology}

The interfacial rheological measurements were done using a Physica MCR 301 Dynamic Shear Rheometer (Physica Meptechnik GmbH, Stuttgart, Germany), with a stainless steal biconical disk (radius of disk, $\mathrm{Rb}$, of $34.125 \mathrm{~mm}$ and disk double angle $(2 \alpha)$ of $10^{\circ}$ ). A thermostated vessel (inner radius, Rc, $40 \mathrm{~mm}$ ) was inserted in the measuring plate of the rheometer. Aqueous solutions (118 mL) of MPGM $(4,5,6 \%$ w/w) at $\mathrm{pH} 7.0$ prepared $24 \mathrm{~h}$ before, were carefully spilled into the thermostated vessel. Afterwards the rheometer motor drive was lowered until the stainless steel biconical disk was placed at the MFGM solution surface. Then $118 \mathrm{~mL}$ of $\mathrm{CO}$ or $\mathrm{CO}+\mathrm{PGPR}$ (were 
carefully poured with help of a glass rod unto the vertical wall of the vessel until the oil formed a layer above the MFGM solution (Román-Guerrero et al., 2009). The age of the interface was taken from the moment the last droplet of oil was poured in.

\subsubsection{Interfacial shear viscosity}

The different MFGM interfacial films were submitted to a constant disk angular velocity $(\Omega)$ of $1.76 \times$ $10^{-4} \mathrm{rad} / \mathrm{s}$. The necessary torque $(\mathrm{M})$ required for maintaining the steady rotational speed and angular displacement of the disk with time $\left(\theta_{b}\right)$ was monitored every $10 \mathrm{~s}$ for $15 \mathrm{~min}$ with the rheometer softwane. Plots of interfacial shear strain $\left(\gamma^{\text {ind }}\right)$ versus interfacial shear stress $\left(\sigma^{\text {inn}}\right)$ were obtained from the equipment software, and were used to determine the region in which the torque and/or interfacial stress at the interface attains steady-state behavior, which were used for calculating the interfacial shear viscosity $\left(\eta^{\text {in }}\right)$ with Eq. (2) (Pérez-Orozco et al., 2004):

$$
\eta^{\text {int }}=\frac{M}{4 \pi \Omega}\left(\frac{1}{R_{b}^{2}}-\frac{1}{R_{c}^{2}}\right)
$$

\subsubsection{Interfacial creep compliance-time studies}

The different MFGM and MFGM/PGPR interfacial films creep compliance-time behavior was carried out by subjecting them to a constant $\sigma^{i \text { in }}$ of 0.5658 $\mathrm{mN} / \mathrm{m}$ during $60 \mathrm{~min}$, after which $\sigma^{i n}$ was withdrawn, and the stress relaxation of the interfacial films was followed for further $7 \mathrm{~min}$. The selected shear stress felt within the linear viscoelastic region of all of the interfacial films.

Plots of $J(t)$ versus $t$ for the different interfacial films were obtained and the equipment software provided the values of the parameters of the following equation (Pérez-Orozco et al., 2011):

$$
J(t)=J_{0}+J_{m}\left(1-e^{-(t / \lambda m)}\right)+J_{N}
$$

where $J_{0}=\left(1 / E_{0} ; E_{0}\right.$ is the interfacial instantaneous elastic modulus) is the interfacial instantaneous elastic compliance in which bonds between the primary structural units are stretched elastically: $J_{m}=\left(1 / E_{R}\right.$. $E_{R}$ is the interfacial retarded elastic modulus) is the interfacial mean retarded compliance of all the bonds involved: $\lambda_{m}=\left(J_{m} / \eta_{m}: \eta_{m}\right.$ is the interfacial mean viscosity associated with retarded elasticity) is the interfacial mean retardation time; and $J_{N}=$ $\left.t / \eta_{N}\right)$ is the interfacial Newtonian compliance, which is characterized by an interfacial viscosity $7 \mathrm{~N}$. All measurements were carried out at $25^{\circ} \mathrm{C}$.

\subsection{Multiple emulsions preparation}

Three multiple emulsions (ME) were prepared at 20 $\pm 2{ }^{\circ} \mathrm{C}$ using a two-stage emulsification procedure (Lobato-Calleros et al., 2009). In the first stage, a $\mathrm{W}_{\mathrm{L}} / \mathrm{O}$ emulsion was made with a 0.3 dispersed mass fraction $\left(\phi_{1}\right)$. The aqueous phase $\left(\mathrm{W}_{1}\right)(29.9 \mathrm{~g}$ of distilled water $+0.1 \mathrm{~g}$ of $\mathrm{CMC}$ ) was poured drop-wise with continuous agitation into the oil phase $(\mathrm{O})(66.8$ $\mathrm{g}$ of $\mathrm{CO}+3.2 \mathrm{~g}$ of PGPR) with the help of a high shear Ultra-Turrax T50 basic homogenizer (IKA Works, Inc. Wilmington, USA) operated at $6400 \mathrm{rpm}$ during 5 $\mathrm{min}$. In the second stage the requisite amount of $\mathrm{W}_{1} / \mathrm{O}$ primary emulsion was re-emulsified ( $6400 \mathrm{rpm}$ for 4 min) into 4,5 , and $6 \%$ w/w MFGM solutions adjusted at $\mathrm{pH} 7.0$, yielding the ME with a 0.3 dispersed mass fraction $\left(\phi_{2}\right)$ that were coded as: $\mathrm{ME}_{4 \%}$. $\mathrm{ME}_{5 \%}$, and $\mathrm{ME}_{6 \mathrm{f}}$, respectively. During the emulsification process an ice bath was used to avoid temperature rising above $20 \pm 2{ }^{\circ} \mathrm{C}$.

\subsection{Morphology and size of the ME droplets}

The morphology of the ME droplets of the multiple emulsions was determined using an optical microscope (Olympus BX45, Olympus Optical Co., Tokyo, Japan) coupled to an image analyzer system (digital Olympus camera C3030, Olympus America Inc., USA).

The initial mean surface-volume droplet size $\left(d_{3,2}\right)$ and its evolution with storage $\left(4 \pm 1^{\circ} \mathrm{C}\right)$ time $(3,7$, 10,15 and 21 d) of the ME was determined with a Malvern particle size analyzer series 2600 (Malvern Instruments, Malvem, Worcestershire, UK).

\subsection{Oscillatory rheological properties of the $M E$}

The oscillatory rheological behavior of the ME was determined after I day of preparation with the Physica MCR 301 rheometer coupled to double gap concentric cylinders measuring system. ME were loaded into the measuring system and left to rest for $15 \mathrm{~min}$ for structure recowery and for temperature equilibration $\left(25^{\circ} \mathrm{C}\right)$. Dynamic amplitude sweeps $(0.01-10 \%$ strain) were performed under a constant frequency (1 $\mathrm{Hz}$ ), in order to determine the linear viscoelastic range, where rheological properties are not strain or stress dependent. From the linear viscoelastic range a strain level of $0.2 \%$ was chosen to perform frequencies sweeps at $0.01-10 \mathrm{~Hz}$. The storage modulus $\left(\mathrm{G}^{\prime}\right)$ and 
the loss modulus $\left(G^{\prime \prime}\right)$ as a function of frequency were obtained from the equipment software.

\subsection{Data analysis}

All of the experiments were done in triplicate using a randomized experimental design. Rheological properties of MFGM interfacial films were analyzed using simple classification variance analysis and whenever it was appropriate, Tukey's test was used in order to determine differences between the means. The significance was determined at $\mathrm{p} \leq 0.05$. Data analysis was performed using Statgraphics Plus software (Statistical Graphics Corp., Manugistics, Inc. Cambridge, MA, USA).

\section{Results and discussion}

\subsection{Yield and chemical composition of the MFGM}

The yield of MFGM was $3.2 \pm 0.3 \mathrm{~g} / \mathrm{L}$ of cream. This result is close to that $(3.6 \pm 0.3 \mathrm{~g} / \mathrm{L})$ reported by Fong et al. (2007). The protein, lipids and total phospholipids contents of the MFGM were of 42.38 $\pm 1.70,45.7 \pm 1.4$ and $30.05 \pm 1.2 \%$, respectively. Literature data on the composition of the MFGM are highly variable due to differences in isolation method. type of raw material, pre-treatment of buttermilk or cream, purification and analysis techniques. Singh (2006) informed that protein accounts for 25-60\% of the mass of the MFGM, depending on the isolation method chosen and the sample history. Fong et al. (2007) reported a protein and lipid contents of 22.3 $\pm 1.5 \%$ and $71.8 \pm 1.7 \%$, respectively, in the pellet fraction of MFGM. Kanno and Kim (1990) obtained a MFGM containing $28 \%$ of protein and $64 \%$ lipid. Bezeloues et al. (2009) reported $55 \%$ of protein, 37.9 $\%$ of lipids and $25 \%$ of phospholipids contents for MFGM.

The MFGM phospholipids are primarily phosphatidyl choline (PC), phosphatidyl ethanolamine (PE), and sphingomyelin (SM), with small amounts of phosphatidyl serine and phosphatidyl inositol (PI) (Thompson and Singh, 2006). All of these phospholipids possess surface active properties. Interfacial rheology is an important method to obtain knowledge and understanding of interfacial activity and system stability (He et al., 2008).

\subsection{Interfacial rheological properties of the MFGM films}

\subsubsection{Interfacial shear viscosity}

When two droplets in a liquid environment approach one another, the behavior of the system is govemed by the interplay of hydrodynamic forces and surface forces. The hydrodynamic forces lead to viscous flow of the liquid medium from between the droplets and to distortion of the form of the droplets because of the pressure developed between them. The radial flow of fluid from between them the droplets exerts a shearing force on them, tending to generate a circulation of liquid within each droplet. The distortion of the droplets is opposed by surface (interfacial) tension. because any departure from spherical form involves an increase of surface area (Kitchener and Musselwhite, 1969). While interfacial viscosity cannot cause static metastability, it might assist in dynamic stabilization, by slowing up the extrusion of liquid from between approaching surfaces between emulsion droplets.

Surface shear stress was measured as a function of strain for the MFGM at different concentrations and at aging times (Fig. 1). All of the MFGM concentrations showed similar shear-strain profiles. Independently of the MFGM concentration used, a finite aging time ( $12 \mathrm{~h}$ for $4 \%$ of MFGM, and 8 h for 5 and $6 \%$ of MFGM) had to elapse before the interfacial film produced an elastic response, ie. the increase in $\sigma^{i n}$ is proportional to increase in $\gamma^{i n}$. The initial interfacial film forming induction period could be influenced by the diffusion rate of the surface-active MFGM components (proteins and phospholipids) and its interfacial affinity (Beverung et al., 1999). It is typical of macromolecular surfactants that their adsorption is very slow to approach equilibrium and is practically irreversible (Kitchener and Musselwhite, 1969). As continued interfacial adsorption and rearrangements of the surface-active components occurred greater number of molecular interfacial contacts caused an elastic film forming. which suffered reversible structural changes doe to bond stretching between molecules without rupture. As aging time increased, the magnitude reached by $\sigma^{\text {inu }}$ in the elastic region increased, and was higher as the MFGM concentration was higher. The curves exhibiting an elastic response showed a maximum in $\sigma^{i n}$, related with the amount of stress that the films can withstand before their structure yields, followed by a decrease in $\sigma^{i n t}$, indicating that the elastic limit of the adsorbed layer has been superseded, and that 
a viscous deformation mechanism begins to occur. As $\gamma^{\text {in }}$ continues increasing, $\sigma^{\text {int }}$ continues dropping until a steady-state shear-stress value is reached (Ganzevles ef al., 2006). The maximum steady-state shear-stress value was obtained after approximately 36 $\mathrm{h}$, independently of MFGM concentration used. At this aging time the maximum $\sigma^{\text {iny }}$ values obtained varied as follows $1.9 \mathrm{mN} / \mathrm{m}$ for $4 \%$ MFGM film $<2.2 \mathrm{mN} / \mathrm{m}$ for $5 \%$ MFGM film $<2.3 \mathrm{mN} / \mathrm{m}$ for $6 \%$ MFGM film (Fig. 1); while the steady-state $\sigma^{\text {in }}$ values varied as follows $1.31 \mathrm{mN} / \mathrm{m}$ for $4 \%$ MFGM $<1.64 \mathrm{mN} / \mathrm{m}$ for $5 \%$ MFGM film $<1.71 \mathrm{mN} / \mathrm{m}$ for $6 \%$ MFGM film. It can be seen that interfacial films at higher MFGM concentration required a larger $\sigma^{\text {ind }}$ for achieving a given $\gamma^{\text {in }}$.

The interfacial stress (torque) at the interface where the steady-state behavior was attained was used for calculating the $\eta^{i n}$. Figure 2 shows the $\eta^{\text {ini }}$ versus time plots for the films using different MFGM concentrations. A marked increase in the $\eta^{\text {in }}$ occurred with aging time, indicating the interactions among the proteins and phospholipids molecules at the interface depended on their total concentration. The $\eta^{\text {int }}$ value reached after $36 \mathrm{~h}$ was higher as the MFGM concentration increased as follows: $1029.49 \mathrm{mNs} / \mathrm{m}$ $(4 \%), 1292.01 \mathrm{mNs} / \mathrm{m}(5 \%)$ and $1352.26 \mathrm{mNs} / \mathrm{m}$ $(6 \%)$. Pérez-Orozco et al. (2004) reported increasing $\eta^{\text {int }}$ values for mesquite gum-chitosan interfacial films with aging time. Waninge ef al. (2005) reported that interfacial films made from a mixture of proteins and phospholipids resembling MFGM tended to form more complex structures than an adsorbed monolayer.

\subsubsection{Interfacial creep compliance-time studies}

The mechanical properties of macromolecular stabilized interfaces have been correlated with droplet stability. The mechanics of the approach of two drops in a fluid medium can give rise to several phenomena most leading to droplets surface deformation, which on turn lead to the thinning out of interfacial films. to their collapse and to droplets coalescence. It has been proposed that interfacial films exhibiting high elasticity possess a better capability of "healing" disturbances at the interfacial region, so that time of coalescence of the droplets is greatly extended (Kitchener and Musselwhite, 1969). The interfacial creep compliance-time study is a non-destructive test permitting the determination of rheological parameters under conditions that approach the state of the sample at rest: this allows elucidating a more precise picture of the actual film (Román-Guenero
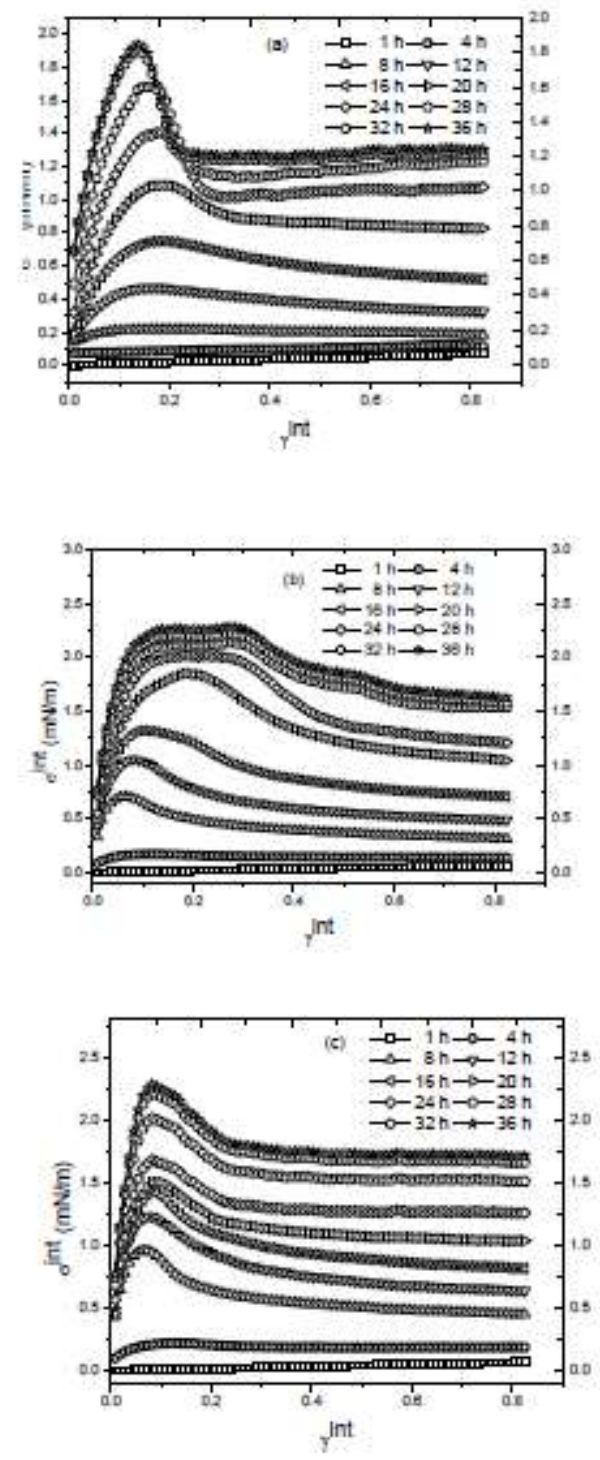

Fig. 1. Shear stress-strain relationship with aging time for MFGM films at different concentrations: (a) $4 \%$, (b) $5 \%$, and (c) $6 \%$.

et al., 2009). All of the MFGM and MFGM/PGPR interfacial films exhibited typical interfacial creep compliance-time curves (Fig. 3), indicating that they exhibited viscoelastic behavior. 


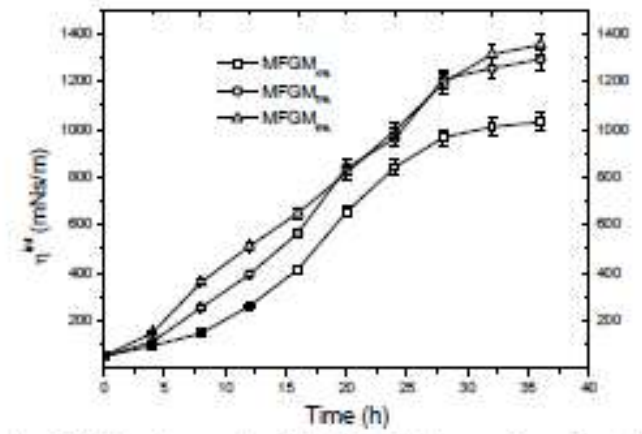

Fig. 2. Development of interfacial shear viscosity of MFGM films at different concentrations with aging time.

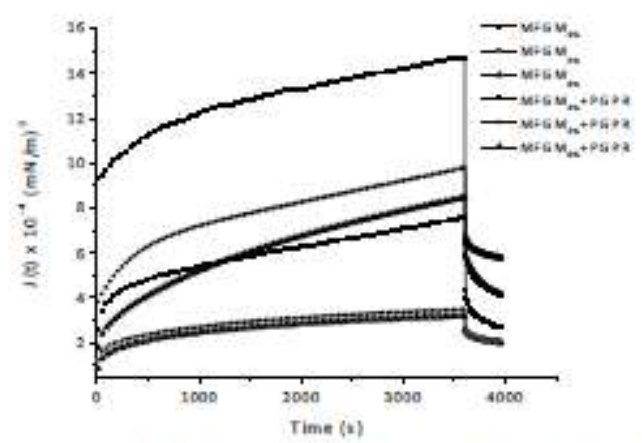

Fig. 3. Creep Compliance-time curves of the MFGM and MFGM + PGPR films aged $36 \mathrm{~h}$.

The viscoelastic parameters characterizing each film are given in Table 1. Analysis of instantaneous interfacial compliance modulus $\left(J_{0}\right)$, which is related with the instantaneous reversible deformation suffered by the strain applied to the film, indicales that as MFGM concentration increased (whether alone or combined with PGPR $)$ the $E_{0}=\left(1 / J_{0}\right)$ value of the films increased. Thus, $E_{0}$, which provides a measure of elastic strength on the bonds making up the interfacial network structure (Lobato-Calleros et al., 2000) was higher for MFGM $_{6 \%}>$ MFGM $_{5 q}>$ MFGM $_{64}+$ $\mathrm{PGPR}>\mathrm{MFGM}_{4 \%}>\mathrm{MFGM}_{5 \%}+\mathrm{PGPR}>\mathrm{MFGM}_{4 \alpha}$ + PGPR. The retarded interfacial elastic compliance region parameters $J_{m}$ and $\lambda_{m}\left(J_{m} / \eta_{m}\right)$. where bonds break and reform but not at the same rate, can provide more detailed information regarding the nature of the interfacial films (Román-Guenrero ef al., 2009). In particular $\lambda_{m}$, which is the time taken for the delayed strain to reach approximately $63.2 \%$ (1-1/e), may be considered a measure of the complexity of the type and diversity of bonds making up the interfacial films. The more complex the structure, longer retardation times are needed to characterize the types of bonding that takes place (Lobato-Calleros et al., 2000).

Significantly higher values for $\lambda_{m}$ were displayed as the MFGM concentration increased, but were significantly lower for the MFGM + PGPR films than for their pure MFGM counterparts. Likewise, $J_{N}$ (= $\left.t / \eta_{N}\right)$ indicates that steady state deformation is reached when the creep deformation is mainly governed by viscous flow which is seen as a linear increase of the creep curve (Van Bockstaele of al., 2011). Higher $\eta_{N}$ values were exhibited as the MFGM concentration increased, but again, $\eta_{N}$ values decreased for MFGM + PGPR films in comparison to the MFGM films. For proteins $\eta_{\mathrm{V}}$ and $\mathrm{G}^{\prime}$ are usually much higher than for low molecular weight surfactants (Murray, 2011). It is evident that there is a displacement of the adsorbed MFGM by PGPR. Because PGPR has a strong attraction for oil, its molecules must be, at least to some extent, in a dissolved state in the oil phase. Most of PGPR hydrocarbon chain lies deeply within the oil phase, and a small portion of the hydrophilic part is located at the oil-water interface. On the other hand, the MFGM molecules are more attracted to the water phase with only the hydrophobic mojeties anchoring at the oil-water interface and the bulk of the molecules are projected into the aqueous phase (Doxastakis and Sherman, 1983). The adsorted PGPR molecules disrupt MFGM-MFGM molecules interaction at the interface due to a lubricating action, but do not completely displace the MFGM molecules from the interface, resulting in a decrease of the viscoelastic properties (Dickinson, 1991).

\subsection{Morphology and stability of the $M E$}

All of the fresh ME were characterized for exhibiting type C morphology (Garti, 1997), i.e. they were made up by spherical oil droplets containing within them a large number of water droplets (Fig. 4). The initial mean $d_{3,2}$ of the external droplets and its change with storage time was considered as a measure of the relative stability between the ME According to the Fig. 5, we envisaged that the MFGM concentration in the external aqueous phase influenced the stability of the ME and the initial $d_{3,2}$ values. Lower concentrations of MFGM produced larger initial $\mathrm{d}_{3.2}$ as follows: ME $4 \%(2.75 \mu \mathrm{m})>\mathrm{ME}_{5 \%}(2.51$ $\mu \mathrm{m})>\mathrm{ME}_{64}(2.39 \mu \mathrm{m})$. Higher initial $d_{1,2}$ resulted in a droplet size polydispersity (noted in deviation bars in 
Table I. Viscoelastic parameters of the MFGM and MFGM + PGPR interfacial films

\begin{tabular}{|c|c|c|c|c|c|c|}
\hline Film code & $\begin{array}{c}J_{0} \times 10^{4} \\
(\mathrm{mN} / \mathrm{m})^{-1}\end{array}$ & $\begin{array}{c}E_{0} \times 10^{-4} \\
(\mathrm{mNm})\end{array}$ & $\begin{array}{l}J m \times 10^{4} \\
(\mathrm{mN} / \mathrm{m})^{-1}\end{array}$ & $\begin{array}{l}\lambda_{m} \\
\text { (s) }\end{array}$ & $\begin{array}{c}J_{N} \times 10^{4} \\
(\mathrm{mN} / \mathrm{m})^{-1}\end{array}$ & $\begin{array}{c}\eta_{N} \times 10^{4} \\
(\mathrm{mNs} / \mathrm{m})^{-1}\end{array}$ \\
\hline MPGM $_{\triangle Q}$ & $2.6 \pm 0.1^{b e}$ & $0.4 \pm 0.0^{b}$ & $4.8 \pm 0.2^{a}$ & $950.2 \pm 23.0^{f}$ & $3.0 \pm 0.1^{b c}$ & $1197.0 \pm 54.3^{a}$ \\
\hline MFGM & $1.2 \pm 0.1^{a}$ & $0.8 \pm 0.0^{c}$ & $2.2 \pm 0.2^{a b}$ & $1164.8 \pm 19.0^{d}$ & $0.8 \pm 0.1^{a}$ & $4456.3 \pm 32.2^{b}$ \\
\hline MFGM $_{6 \%}$ & $0.9 \pm 0.0^{a}$ & $1.2 \pm 0.1^{d}$ & $1.8 \pm 0.1^{a b}$ & $1252.9 \pm 15.3^{e}$ & $0.7 \pm 0.0^{a}$ & $4633.2 \pm 57.2^{b}$ \\
\hline $\mathrm{MFGM}_{4 \alpha}+\mathrm{PGPR}$ & $9.2 \pm 0.7^{d}$ & $0.1 \pm 0.0^{a}$ & $2.5 \pm 0.2^{b}$ & $322.9 \pm 10.6^{a}$ & $3.6 \pm 0.3^{c}$ & $1003.7 \pm 70.1^{a}$ \\
\hline MFGM $_{5 q_{e}}+$ PGPR & $3.7 \pm 0.3^{c}$ & $0.3 \pm 0.0^{a b}$ & & $472.4 \pm 14.7^{b}$ & $3.4 \pm 0.1^{b c}$ & $1052.1 \pm 37.2^{a}$ \\
\hline $\mathrm{MFGM}_{6 \%}+\mathrm{PGPR}$ & $1.5 \pm 0.6^{a b}$ & $0.7 \pm 0.2^{c}$ & $1.4 \pm 0.1^{a}$ & $488.8 \pm 15.2^{b}$ & $3.0 \pm 0.1^{b}$ & $1213.1 \pm 40.3^{a}$ \\
\hline
\end{tabular}

Means in a column followed by different letters are significantly different $(p \leq 0.05)$. $J_{0}$ : interfacial instantaneous compliance; $E_{\mathrm{D}}$ : interfacial instantaneous elastic modulus; $J_{m}$ : interfacial mean compliance; $\lambda_{m}$ : interfacial mean retardation time; $J_{S:}$ interfacial Newtonian compliance $\eta_{N}$ : interfacial viscosity.
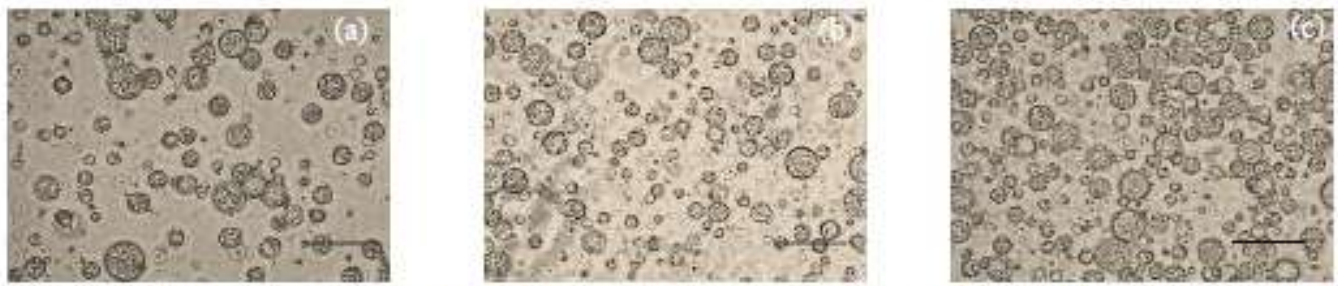

Fig. 4. Optical microscope images of ME droplets made up by spherical oil droplets containing within them a large number of water droplets: (a) $\mathrm{ME}_{4 \%}$, (b) $\mathrm{ME}_{5 \%}$, and (c) $\mathrm{ME}_{6 \%}$. Scale bar $=10 \mu \mathrm{m}$.

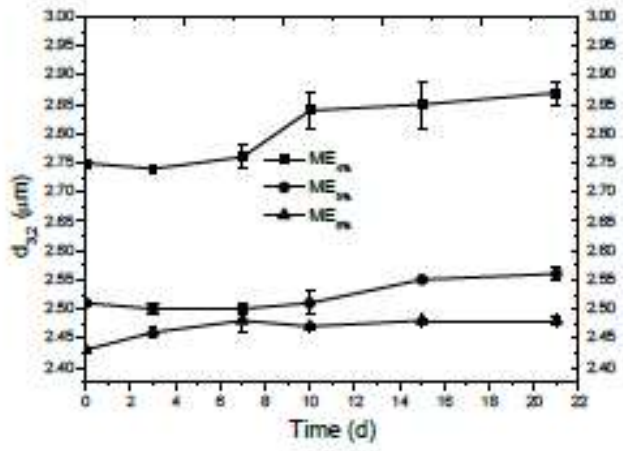

Fig. 5. Changes in the mean surface-volume droplet size $\left(d_{3,2}\right)$ of the ME with aging time.

Fig. 5) throughout storage time. Smalker initial $d_{3,2}$ produced smaller increases in droplet size during the 21 days storage time. Thus, the relative increases of $\mathrm{d}_{3,2}$ between $t=0 \mathrm{~d}$ and $t=21 \mathrm{~d}$ was as follow: $\mathrm{ME}_{4 \%}=4.4 \%, \mathrm{ME}_{5 \%}=2 \%$, and $\mathrm{ME}_{6 \%}$ $=1.6 \%$. These results indicate that although all of the ME emulsions were quite stable, those made using $6 \%$ of MFGM suffered the smallest droplet size variation, so that they may be considered to be more stable. The destabilization processes that the ME may suffer are varied; for example, the outer droplet interface may coalesce with one or more multiple emulsion droplets; the individual internal aqueous droplets can be expelled sequentially from the multiple emulsions droplets; gradual shrinkage of the internal droplets is possible due to osmotic gradient between the inner and continuous aqueous phases, when net mass transport of water occurs from the inner phase to the outer continuous phase through the oil film acting as a "semi-permeable membrane"; and conversely, when the osmotic gradient acts in the opposite direction, water diffusion through the oil film from the continuous phase into the encapsulated aqueous droplets will produce swelling of these inner droplets (Hernández-Marin et al., 2013). However, it has been established that adequate combinations of emulsifiers at the inner as well at the outer phase have beneficial effects on the stability of the ME (Garti, 1997). The optimum use of emulsifiers in ME formulation depends on their interfacial rheological properties (MaldonadoValderrama and Rodríguez-Patino, 2010). A positive correlation between emulsion stability against droplet coalescence and surface shear viscosity has been found in experiments with oil-in-water emulsion-sized droplets introduced into the vicinity of a planar oilwater interface aged with a pure protein (Dickinson et al., 1988). 


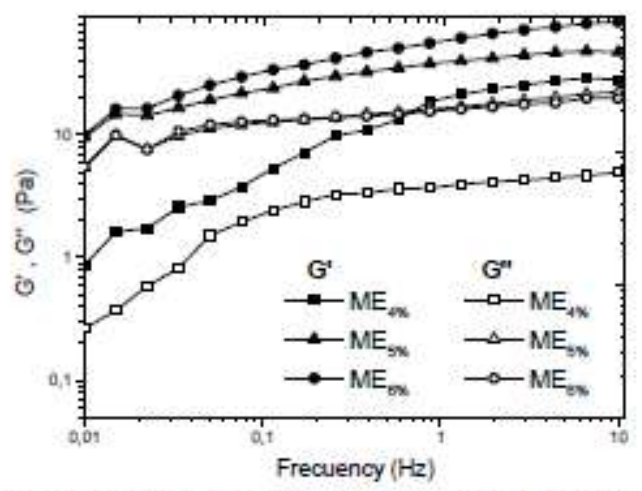

Fig. 6. Evolution of the storage $\left(G^{\prime}\right)$ and loss $\left(G^{\prime \prime}\right)$ moduli of the ME with frequency sweep at $0.2 \%$ strain.

In addition, highly viscoelastic protein films tend to dampen down surface fluctuations, thus inhibiting the mechanism responsible for film rupture (Dickinson, 1992). The stability results of the ME tend to confirm that the stability of the ME was closely related to the interfacial rheological properties of the MFGM films.

\subsection{Oscillatory rheological properties of the $M E$}

Small-amplitude dynamic oscillatory shear tests are a powerful tool to obtain information about the microscopic structure of viscoelastic materials like emulsions, prowiding the values of the storage (G') and loss (G') moduli. $G^{\prime}$ is proportional to the extent of the elastic component of the system, and $G^{\prime}$ is proportional to the extent of the viscous component of the system (Wulff-Pirez et al., 2011). All of the ME made with different MFGM concentrations showed increases in $\mathrm{G}^{\prime}$ and $\mathrm{G}^{\prime \prime}$ as a function of frequency, displaying higher $G^{\prime}$ than $G^{\prime \prime}$ values over the whole frequency range studied (Fig. 6). Both, G' and G" were frequency dependent, although this dependency decreased as MFGM concentration increased. The kind of behavior depicted in figure 6 is typical of concentrated emulsions having a weak gel structure that arises from flocs held together rather strongly by polymer bridges, but that are nonetheless susceptible to reorganization on aging and in the presence of shear fields (Dickinson and Pawlowsky, 1996; Barnes, 2004). G" and G" values increased with increasing MFGM concentration and this behavior seems to be closely interconnected with the $d_{3,2}$ shown by the ME. Smaller $d_{3,2}$ imply higher numbers of ME droplets per unit volume and a more tightly interwoven floc structure.

\section{Conclusions}

Interfacial rheology results indicated that higher concentration of pure milk fat globule membrane (MFGM) produced films with higher interfacial instantaneous elastic modulus $\left(E_{0}\right): 0.4 \mathrm{mN} / \mathrm{m}$ for 4 $\% ; 0.8 \mathrm{mN} / \mathrm{m}$ for $5 \%$; and $1.2 \mathrm{mN} / \mathrm{m}$ for $6 \%$; and higher interfacial viscosity $\left(\eta_{\mathrm{N}}\right) 1197.0 \mathrm{mNs} / \mathrm{m}$ for 4 $\% ; 4456.3 \mathrm{mNs} / \mathrm{m}$ for $5 \%$ and $4633.2 \mathrm{mNs} / \mathrm{m}$ for 6\%. When PGPR was added to the oil phase MFGM molecules were displaced in some extent from the interface resulting in a weakened interfacial film, but still mechanically strong. A close interelationship was found to exist between the stability of the multiple emulsions and the interfacial rheological properties of the MFGM + PGPR films Multiple emulsions stabilized by MFGM in different concentrations displayed frequency dependent viscoelastic properties where the storage modulus had higher values than the loss modulus over the whole frequency range studied. This behavior is characteristic of weakgel structures arising from polymer bridging among flocs. Higher MFGM concentration produced higher viscoelastic moduli and lower frequency dependence. thus suggesting a close correspondence with multiple emulsion droplet size.

\section{References}

AOAC (1995). Association of Official Analytical Chemists, 16th edn. Association of Official Analytical Chemists, Arlington.

Bames, H.A. (2004). The rheology of emulsions. In: Emulsions: Structure stability and interactions Interface Science and Technology Vol. 4, (D.N. Petsev, ed.), Pp. 721-759. Elsevier B.V., Amsterdam, Netherlands.

Beverung. C.J., Radke, C.J. and Blanch, H.W. (1999). Protein adsorption at the oil/water interface: characterization of adsorption kinetics by dynamic interfacial tension measurements. Biophysical Chemistry 81, 5980.

Bezelgues, J.B., Morgan, F., Palomo, G., CrossetPerrotin, L. and Ducret, P. (2009). Short communication: Milk fat globule membrane 
as a potential delivery system for liposoluble nutrients. Journal of Dairy Science 92, 2524 2528.

Corredig, M. and Dalgleish, D.G. (1998). Buttermilk properties in emulsions with soybean oil as affected by fat globule membrane-derived proteins. Journal of Food Science 63, 476-480.

Crook, T., Tinklenberg, J., Yesavage, J., Petrie, W., Nunzi, M. and Massari, D. (1991). Effects of phosphatidylserine in age-associated memory impairment. Neurology 41, 644-649.

Danthine, S., Blecker, C., Paquot, M., Innocente, N. and Deroanne, C. (2000). Progress in milk fat globule membrane research: A review. Lait 80 , $209-222$.

Dickinson, E., Murray, B.S. and Stainsby, G. (1988). Coalescence stability of emulsionsized droplets at a planar oil-water interface and the relationship to protein film surface rheology. Journal of the Chemical Society, Faraday Transactions 1: Physical Chemistry in Condensed Phases 94, 871-883.

Dickinson, E (1991). Competitive adsorption and protein-surfactant interactions in oil-in-water emulsions. In: Microemulsions and Emulsions in Foods, (M. El-Nokaly and D. Comell, eds.), Pp. 114-128. American Chemical Society, Washington, DC.

Dickinson, E (1992). Interfacial interactions and the stability of oil-in-water emulsions. Pure and Applied Chemistry 64, 1721-1724.

Dickinson, E. and Pawlowsly, K. (1996). Rheology as a probe of protein-polysaccharide interactions in oil-in-water emulsions. In: Gums and Stabilizers for the Food Industry 8, (G.O. Phillips, P.A. Williams and D.J. Wedlock, eds.), Pp. 18I-191. IRL Press, Oxford, UK.

Doxastakis, G. and Sherman, P. (1983). The influence of the interaction of mono- and diglycerides with milk proteins on the rheology and stability of food emulsions (corn-in-oilwater emulsions). In: Instrumental Analysis of Foods Vol. 2 Dairy Products; Food Quality; Food Composition, (G. Charalambous and G. Inglett, eds.), Pp. 219-285. Academic Press, New York, NY.
Fong, B.Y., Norris, C.S. and MacGibbon, A.K.H. (2007). Protein and lipid composition of bovine milk-fat-globule membrane. International Dairy Journal 17, 275-288.

Garti, N. (1997). Progress in stabilization and transport phenomena of double emulsions in food applications. Lebensmittel Wissenschaf und Technologie 30, 222-235.

Garzevles, R.A., Zinoviadou, K., van Vliet, T. Cohen-Stuart, M.A. and de Jongh, H.H.J. (2006). Modulating surface rheology by electrostatic protein/polysaccharide interactions. Langmuir 22, 10089-10096.

He, Q., Zhang, Y., Lu, G., Miller, R., Mohwald, $\mathrm{H}$. and Li, J. (2008). Dynamic adsorption and characterization of phospholipid and mixed phospholipid/protein layers at liquid/liquid interfaces. Advances in Colloid and Interface Science 140, 67-76

Henry, J.V.L., Fryer, P.J., Frith, W.J. and Norton, L.T (2010). The influence of phospholipids and food proteins on the size and stability of model submicron emulsions. Food Hydrocolloids 24, 6671.

Hernández-Marín, N.Y., Lobato-Calleros, C. and Vernon-Carter, EJ. (2013). Stability and rheology of water-in-oil-in-water multiple emulsions made with protein-polysaccharide soluble complexes. Journal of Food Engineering 119, 181-187.

Jensen, R.G. (2002). The composition of bovine milk lipids: January 1995 to December 2000. Journal of Dairy Science 85, 295-350.

Kanno, C. (1989). Emulsifying properties of bovine milk fat globule membrane in milk fat emulsion: conditions for the reconstitution of milk fat globules. Journal of Food Science 56, 1219 1223.

Kanno, C. and Kim, D.H. (1990), A simple procedure for the preparation of bovine milk fat globule membrane and a comparison of its composition enzymatic activities, and electrophoresis properties with those prepared by other methods. Agricultural and Biological Chemistry Tokyo 54, 2845-2854. 
Kitchener, J.A. and Musselwhite, P.R. (1969). The theory of stability of emulsions. In Emulsion Science, (P. Sherman, ed.), Pp. 77 130. Academic Press, London, UK.

Koopman, J., Turkish, V, and Monto, A. (1985). Infant formula and gastrointestinal illness. American Journal of Public Health 75, 477-480.

Lobato-Calleros, C., Aguirre-Mandujano, E, Vernon-Carter, E.J. and Sánchez-Garcia, J. (2000). Viscoelastic properties of white fresh cheese filled with sodium caseinate. Journal of Texture Studies 31, 379-390.

Lobato-Calleros, C., Recillas-Mota, M.T., EspinosaSolares, T., Alvarez-Ramirez, J. and VemonCarter, E.J. (2009). Microstructural and rheological properties of low-fat stimed yoghurts made with skim milk and multiple emulsions. Journal of Texture Studies 40, 657675.

Maldonado-Vaiderrama, J. and Rodríguez-Patino, J.M. (2010). Interfacial rheology of proteinsurfactant mixtures. Current Opinion in Colloid EInterface Science I5, 271-282.

McClements, D.J. and Li, Y. (2010). Structured emulsion-based delivery systems: Controlling the digestion and release of lipophilic food components. Advanced Colloids and Interfaces $159,213-228$.

Murray, B (2011). Rheological properties of protein films. Current Opinion in Colloid \& Interface Science 16, 27-35.

Nalto, H.K. (1975). Modification of the Fiske and SubbaRow method for total phospholipid in serum. Clinical Chemistry 21, 1454-1456.

Parodi, P.W. (2001). Cow's milk components with anti-cancer potential. Australian Journal of Dairy Technology 56, 65-73.

Pérez-Orozco, J.P., Beristain, C. I., Espinosa-Paredes, G., Lobato-Calleros, C and Vemon-Carter, EJ. (2004). Interfacial shear rheology of interacting carbohydrate polyelectrolytes at the wateroil interface using an adapted conventional rheometer. Carbohydrate Polymers 57, 45-54.

Pérez-Orozco, J.P., Barrios-Salgado, E., RománGuerrero, A. and Pedroza-Islas, R. (2011). Interaction of mesquite gum-chitosan at the interface and its influences on the stability of multiple emulsions $\mathrm{W}_{1} / \mathrm{O} / \mathrm{W}_{2}$. Revista Mexicana de Ingeniería Química 10, 487-499.

Roesch, R.R., Rincon, A. and Corredig. M. (2004). Emulsifying properties of fractions prepared from commercial buttermilk by microfiltration Journal of Dairy Science 87, 4080-4087.

Román-Guerrero, A., Orczco-Villafuerte, J., PérezOrozco, J.P., Cruz-Sosa, F, Jiménez-Alvarado, R. and Vemon-Carter, E.J. (2009). Application and evaluation of mesquite gum and its fractions as interfacial film formers and emulsifiers of orange peel-oil. Food Hydrocolloids 23, 708 713.

Sánchez-Juanes, F., Alonso, J.M., Zancada, L. and Hueso, P. (2009). Distribution and fatty acid content of phospholipids from bovine milk and bovine milk fat globule membranes. International Dairy Journal 19, 273-278.

Singh, H. (2006). The milk fat globule membrane. A biophysical system for food applications. Current Opinion in Colloid and Interface Science 11, 154-163.

Spitsberg. V.L. (2005). Invited review: Bovine milk fat globule membrane as a potential nutraceutical. Journal of Dairy Science 88 . 2289-2294.

Thompson, A.K. and Singh, H. (2006). Preparation of liposomes from milk fat globule membrane phospholipids using a microfluidizer. Journal of Dairy Science 89, 410-419.

Van Bockstaele, F., De Leyn, I., Eeckhout, M. and Dewettinck, K. (2011). Non-linear creeprecovery measurements as a tool for evaluating the viscoelastic properties of wheat flour dough. Journal of Food Engineering 107, 50-59.

Vanderghem, C., Bodson, P., Danthine, S., Paquot, M. Deroanne. C. and Blecker, C. (2010), Milk fat globule membrane and buttermilks: from composition to valorization. Biotechnologx Agronomy. Society and Environment 14, 485500.

Waninge, R., Walstra, P., Bastiaans, J. Nieuwenhuijse, H., Nylander, T., Paulsson, M. and Bergenstahl, B. (2005). Competitive adsorption between $\beta$-case in or $\beta$-lactoglobulin 
Dzul-Cauich et al/ Revista Mexicana de Ingeniería Química Vol. 12, №. 3 (2013) 425-436

and model milk membrane lipids at oil-water interfaces, Journal of Agricultural and Food Chemistry $53,716-724$.

Wulff-Pérez, M. Torcello-Gómez, A., MartínRodriguez, A., Galvez-Ruiz, M.J. and de Vicente, J. (2011). Bulk and interfacial viscoelasticity in concentrated emulsions: The role of the surfactant. Food Hydrocolloids 25 , $677-686$.

Ye, A., Singh, H., Taylor, M.W. and Anema, S (2002). Characterization of protein components of natural and heat-treated milk fat globule membranes. International Dairy Journal 12, 393-402. 